\author{
RESEARCH ARTICLE \\ 10.1029/2018JB017015 \\ Key Points: \\ - Electrical conductivity and \\ normalized chargeability of frozen \\ rocks are described in a consistent \\ way \\ - The model is tested against a new \\ database made on nine core samples \\ in the temperature range +20 \\ degrees Celsius and -15 degrees \\ Celsius \\ - A good agreement is obtained \\ between the model and the \\ experimental data
}

Correspondence to: A. Revil,

andre.revil@univ-smb.fr

Citation:

Coperey, A., Revil, A., Abdulsamad, F., Stutz, B., Duvillard, P. A., \& Ravanel, L. (2019). Low-frequency induced polarization of porous media undergoing freezing: Preliminary observations and modeling. Journal of Geophysical Research: Solid Earth, 124 https://doi.org/10.1029/2018JB017015

Received 13 NOV 2018 Accepted 21 APR 2019 Accepted article online 29 APR 2019

(c)2019. American Geophysical Union. All Rights Reserved.

\section{Low-Frequency Induced Polarization of Porous Media Undergoing Freezing: Preliminary Observations and Modeling}

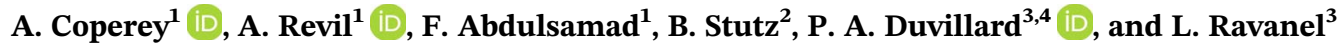 \\ ${ }^{1}$ Université Grenoble Alpes, Université Savoie-Mont Blanc, CNRS, IRD, IFSTTAR, ISTerre, Grenoble, France, ${ }^{2}$ LOCIE, \\ Université Savoie-Mont Blanc, CNRS, Chambéry, France, ${ }^{3}$ Université Grenoble Alpes, Université Savoie-Mont Blanc, \\ CNRS, UMR CNRS, EDYTEM, Le Bourget du Lac, France, ${ }^{4}$ IMSRN, Parc Pré Millet, Montbonnot, France
}

Abstract We investigate the thermal dependence of the complex conductivity of nine porous materials in the temperature range $+20^{\circ} \mathrm{C}$ to -10 or $-15^{\circ} \mathrm{C}$. The selected samples include three soils, two granites, three clay-sands mixes, and one graphitic tight sandstone. A total of 12 experiments is conducted with one sample tested at three different salinities. Our goal is to use this database to extend the dynamic Stern layer polarization model in freezing conditions. We observe two polarization mechanisms, one associated with the effect of the change in the liquid water content and its salinity upon the polarization of the porous material. A second mechanism, at higher frequencies $(>10 \mathrm{~Hz})$, is likely associated with the polarization of ice. At low frequencies and above the freezing point, the in-phase and quadrature conductivities depend on temperature in a predictable way. This dependence is due to the dependence of the mobility of the charge carriers with temperature. Below the freezing point, the in-phase and quadrature conductivity follow a brutal decay with temperature. This dependence is modeled through an exponential freezing curve function. We were also able to determine how the (apparent) formation factor and surface conductivity change with temperature and water content below the freezing point. Our model is able to replicate the data at low frequencies and predicts correctly the fact that the ratio between the normalized chargeability and the surface conductivity is independent of the water content and temperature and equals a well-defined dimensionless number R.

\section{Introduction}

Electrical geophysical methods are increasingly popular to characterize thermal anomalies or to monitor the thermal evolution of the subsurface of the Earth in a variety of extreme environments such as in geothermal systems (e.g., Ghorbani et al., 2018; Hersir \& Bjornsson, 1991) and for permafrost (Doetsch et al., 2015; Kneisel et al., 2008; Krautblatter et al., 2010). These methods provide nonintrusive tomographic techniques that can be used to image temperature changes (Hermans et al., 2014; Revil, Ghorbani, et al., 2018) and therefore complement in situ temperature point or line measurements using temperature probes such as thermocouples or optical fiber. Geophysical methods have also been used to monitor the evolution of rock glaciers and permafrost (e.g., Hauck et al., 2003, 2011; Hilbich et al., 2009; Kellerer-Pirklbauer \& Kaufmann, 2017; Mewes et al., 2017; Mollaret et al., 2018; Springman et al., 2013).

One of these methods is electrical conductivity tomography. Electrical conductivity characterizes the ability of a material to transport charge carriers under the effect of an electrical field (Siemens, 1860). In absence of metallic grains, the electrical conductivity of a porous rock is composed of two contributions: a bulk conductivity occurring through the pore network and an interfacial contribution called surface conductivity and localized on the surface of the grains. In isothermal conditions, the bulk contribution depends in turn on the salinity of the pore water, the water content, and the formation factor (a power law function of porosity; see Archie, 1942). Surface conduction takes place in the electrical double layer coating the surface of the mineral grains (Waxman \& Smits, 1968). This double layer is composed of a Stern layer (Stern, 1924) and a Gouy-Chapmman diffuse layer (Chapman, 1913). The bulk and surface conductivities have distinct dependence on the water content (Waxman \& Smits, 1968). However, electrical conductivity measurements alone cannot be used to separate the bulk and surface conductivity. Induced polarization appears as a complementary technique to electrical conductivity to separate these two conductivity contributions (e.g., Duvillard et al., 2018; Revil, 2013a, 2013b; Weller et al., 2013). 
Induced polarization is a geophysical method dealing with the study of low-frequency $(<10 \mathrm{kHz})$ polarization mechanisms in porous media, especially those related to charge accumulations in the electrical double layer around the grains. Instead of dealing with a single scalar quantity in isotropic media (the electrical conductivity), frequency domain induced polarization deals with a complex-valued conductivity. The in-phase (real) component of this complex conductivity characterizes the ability of the charge carriers to move through the porous material under the action of a primary (applied) electrical field (electromigration; see Waxman \& Smits, 1968). The quadrature (imaginary) component is in a strict sense related to the electrical double layer polarization processes. Generally speaking, it characterizes the ability of a porous media to store reversibly electrical charges under the influence of the primary electrical field (Binley et al., 2005; Revil \& Skold, 2011; Vinegar \& Waxman, 1984). Polarization is responsible for a secondary electrical field/current. In time domain induced polarization, we follow the evolution (relaxation) of this secondary electrical field after the shutdown of the primary electrical field/current.

The dynamic Stern layer model has been developed to provide a consistent picture of electrical conductivity and polarization parameters (especially quadrature conductivity and normalized chargeability) in porous media (Ghorbani et al., 2018; Revil, 2013a, 2013b; Revil, Coperey, et al., 2017; Revil, Le Breton, et al., 2017). This model was tested recently on a variety of porous media including soils (Revil, Coperey, et al., 2017), sandstones (Niu et al., 2016; Revil et al., 2014, Revil, Coperey, Deng, et al., 2018), and volcanic rocks (Ghorbani et al., 2018). This model is able to explain the dependence of the complex conductivity with porosity, water content, cation exchange capacity (CEC) or specific surface area, and temperature.

The influence of temperature on the electrical conductivity itself was explored in the laboratory by Waxman and Thomas (1974), Sen and Goode (1992), Clavier et al. (1984), and Binley et al. (2010), among others. These investigations were done only for temperatures above freezing conditions. The effect of temperature on the complex conductivity of unfrozen materials was explored in various studies (e.g., Ghorbani et al., 2018). There are however very few research works performed to study the complex conductivity of frozen porous media (see Duvillard et al., 2018; Grimm \& Stillman, 2015; Olhoeft, 1977).

In this paper, we investigate the temperature dependence of the complex conductivity during freeze and thaw of nine samples including three soils, one granite, one metamorphic granite, three clay-sands mixes, and one graphitic tight sandstone. A total of 12 experiments was conducted in the temperature range +20 ${ }^{\circ} \mathrm{C}$ to $-15{ }^{\circ} \mathrm{C}$, which is typically the lower temperature bound for most permafrost-affected sites (Brown, 1970). Some of these experiments were done with the same sample but at different salinities (pore water conductivity ranges from 0.01 to $1.0 \mathrm{~S} / \mathrm{m}$ at $25^{\circ} \mathrm{C}, \mathrm{NaCl}$ ). At each temperature, a complete complex conductivity spectrum was performed. So we can observe the effect of the temperature above and below the freezing point upon the complex conductivity spectra and the parameters that can be inferred from these spectra. Our end goal is to use this database to test and extend further the dynamic Stern layer polarization model in freezing conditions especially below $10 \mathrm{~Hz}$. This model can be further applied to the monitoring of permafrost under the action of climate change.

\section{Theory}

Early works regarding electrical conductivity of frozen rocks (e.g., Hoekstra, 1965; Hoekstra \& McNeill, 1973; Ogilvy, 1967; Parkhomenko, 1967; Vershinin et al., 1949) were mostly descriptive or erroneously based on Archie's law (see discussion in Duvillard et al., 2018). Nevertheless, they were showing a strong decrease of the electrical conductivity below the freezing point by comparison with the temperature dependence of this quantity above the freezing point. Induced polarization phenomena were first described by Schlumberger (1920). Very few works have been done regarding the induced polarization of soils and rocks in freezing conditions (e.g., Melnikov et al., 1971; Sidorova \& Fridrikhsberg, 1973; Snegirev et al., 1973). The early explanation was based on the mechanism of membrane polarization, a mechanism based on the gradient of the transference number in porous media (e.g., Marshall \& Madden, 1959), but unfortunately not able to explain the available experimental data, especially the dependence of the quadrature conductivity with salinity.

Our goal is to develop a complete theory of electrical conductivity and chargeability of frozen porous media with testable predictions. We want to push further the observations made in Duvillard et al. (2018) in which 

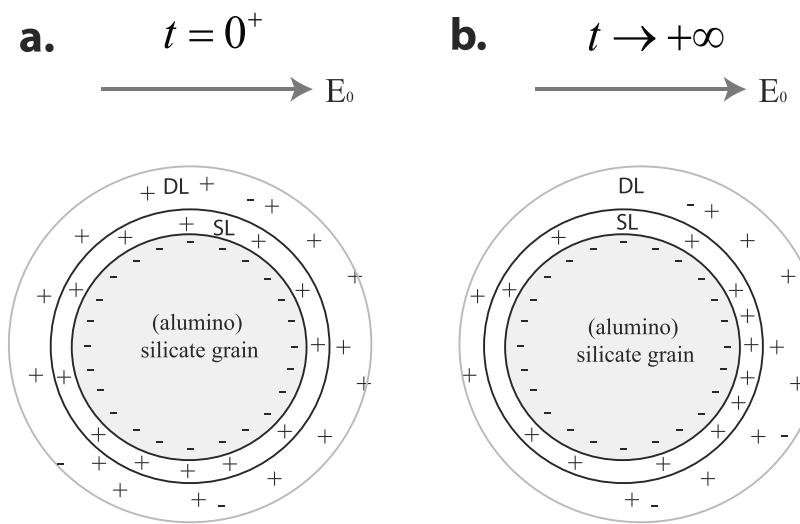

\section{Unpolarized}

$$
\sigma=\sigma_{\infty}
$$

Instantaneous conductivity

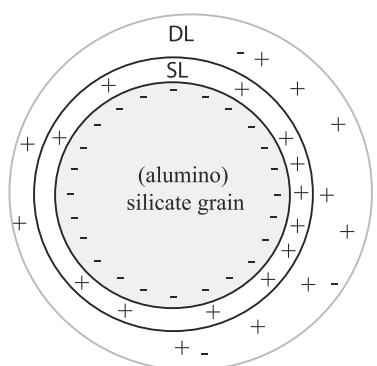

\section{Polarized}

$$
\sigma=\sigma_{0}=\sigma_{\infty}-M_{\mathrm{n}}
$$

DC conductivity

Figure 1. Polarization of the electrical double layer under the influence of an applied electrical field $\mathbf{E}_{0}$. Grains are characterized by charges, depending on the $\mathrm{pH}$ and on the type of mineral (i.e., some isomorphic substitutions in crystalline framework induce some permanent charge, e.g., smectite). This excess of charges is balanced by weakly absorbed counterions in diffuse layer and Stern layer. (a) Just after the application of the primary electrical field $\mathbf{E}_{0}$, all the charge carriers are mobile. The instantaneous conductivity is $\sigma_{\infty}$. (b) If the primary electrical field is applied for a long time, the DC (direct current) conductivity $\sigma_{0}=\sigma_{\infty}-M_{n}$ where $M_{n}$ denotes for the normalized chargeability of the material. Charge carriers of the Stern layer are now blocked at the edge of the grain in the electrical field direction. Now, the conductivity of the material is reduced. The time constant $\tau$ would be the relaxation time required for the charge carriers to come back to their equilibrium situation, that is, to go from the situation described in the right side of the sketch to the situation described in the left side. $\mathrm{DL}=$ Diffuse Layer; $\mathrm{SL}=$ Stern layer.

a preliminary model was recently proposed. In frequency domain induced polarization, a harmonic current is imposed to a porous material and the amplitude of the electrical field and phase shift are measured and used to determine an impedance. In turn, this impedance can be transformed into a complex conductivity $\sigma^{*}=\sigma^{\prime}+i \sigma^{\prime \prime}$ ( $i$ denotes the pure imaginary number) with an in-phase component $\sigma^{\prime}$ characterizing conduction and a quadrature component $\sigma^{\prime}$ characterizing polarization (Bleil, 1953). Lowfrequency $(<10 \mathrm{kHz})$ polarization is fundamentally related to the polarization of the electrical double layer coating the mineral grains of porous media (Revil, 2013b; Weller et al., 2013) even in the case of membrane polarization (Marshall \& Madden, 1959).

In a linear framework, causality implies that polarization is also responsible for the frequency dependence of the in-phase conductivity component. Such (frequency) dispersion of the in-phase conductivity curve can be characterized by a quantity called the normalized chargeability $M_{n}$ equals to $M_{n}=\sigma_{\infty}-\sigma_{0}(\mathrm{~S} / \mathrm{m})$ where $\sigma_{\infty}$ denotes the instantaneous (high frequency) conductivity and $\sigma_{0}\left(<\sigma_{\infty}\right)$ denotes the direct current electrical conductivity. This definition is consistent with the literature where the normalized chargeability is defined as the chargeability divided by the resistivity. As shown in Figure 1, the instantaneous (or high frequency) conductivity is also the measured conductivity just after the application of an external (primary) electrical field. In this situation, all the charge carriers are still mobile. The direct current conductivity is necessarily smaller than the instantaneous conductivity since the charges responsible for the polarization are not available anymore for the conduction process (Figure 1). In other words, at low frequency all the polarization phenomena are fully established for all polarizable length scales and some of charge carriers are blocked, reducing the total electrical field (see Revil, Coperey, et al., 2017). In the next two subsections, we first summarize the dynamic Stern layer model above the freezing temperature and then we discuss how freezing conditions are expected to affect the quadrature conductivity and normalized chargeability of a porous material.

\subsection{The Dynamic Stern Layer Model}

We consider an external harmonic electric field $\mathbf{E}=\mathbf{E}_{0} \exp (+i \omega t)$ applied to a porous material without metallic particles. The complex conductivity can be modelled by Revil, Coperey, et al. (2017)

$$
\sigma^{*}(\omega)=\sigma_{\infty}-M_{n} \int_{0}^{\infty} \frac{h(\tau)}{1+(i \omega \tau)^{1 / 2}} \mathrm{~d} \tau+i \omega \varepsilon_{\infty},
$$

where $\omega$ denotes the angular frequency $(\mathrm{rad} / \mathrm{s}), \varepsilon_{\infty}$ is the permittivity associated at low frequencies with Maxwell-Wagner polarization $(\mathrm{F} / \mathrm{m}), \tau$ is a relaxation time (s), and $h(\tau)$ denotes a (normalized) probability density (kernel) for distribution of the time constants of the porous media. Using a volume averaging method, Revil (2013a) obtained the following expressions of the high- and low-frequency conductivities at saturation $\left(s_{w}=1\right)$

$$
\begin{gathered}
\sigma_{\infty}=\frac{1}{F} \sigma_{w}+\left(\frac{1}{F \phi}\right) \rho_{g} B \text { CEC }, \\
\sigma_{0}=\frac{1}{F} \sigma_{w}+\left(\frac{1}{F \phi}\right) \rho_{g}(B-\lambda) \mathrm{CEC},
\end{gathered}
$$

and the resulting expression of the normalized chargeability is

$$
M_{n}=\left(\frac{1}{F \phi}\right) \rho_{g} \lambda \mathrm{CEC}
$$



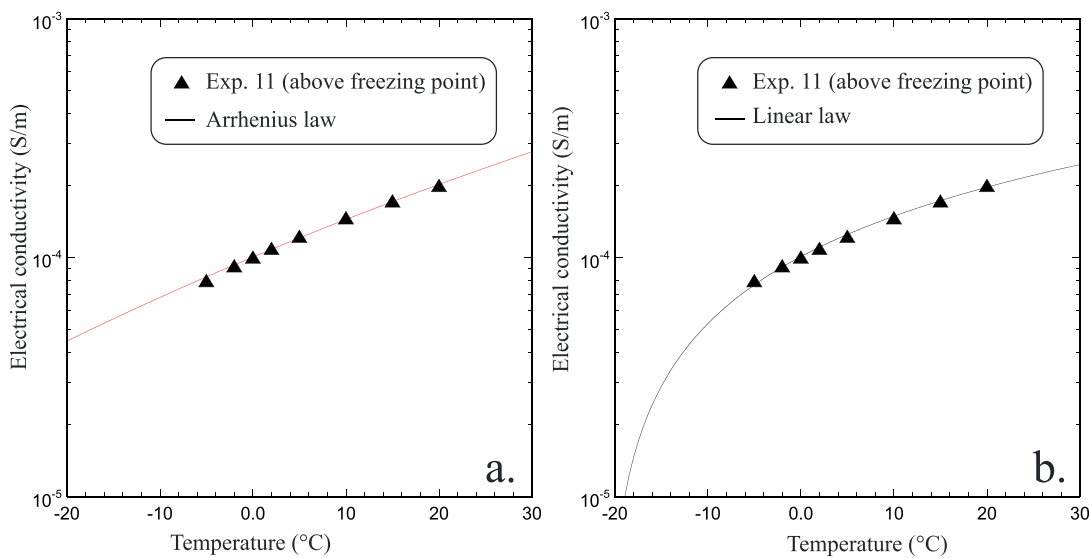

Figure 2. Fit of the conductivity versus temperature data above the freezing point for the data of Experiment 11 (for which the freezing point is at $-5^{\circ} \mathrm{C}$ ). (a) Fit using Arrhenius law $\left(E_{a}=23 \pm 0.4 \mathrm{~kJ} / \mathrm{Mol}\right.$ constant over the temperature range investigated, $\left.\sigma\left(T_{0}=25^{\circ} \mathrm{C}\right)=(2.37 \pm 0.05) \times 10^{-4} \mathrm{~S} / \mathrm{m}, r^{2}=0.998\right)$. (b) Fit with the linear model $\left(\alpha_{T}=0.0217 \pm 0.0002 /{ }^{\circ} \mathrm{C}\right.$, $\left.\left.\sigma\left(T_{0}=25^{\circ} \mathrm{C}\right)=(2.24 \pm 0.02) \times 10^{-4} \mathrm{~S} / \mathrm{m}, r^{2}=0.997\right)\right)$. The two functions (linear and Arrhenius) fit the data equally well but clearly diverge from each other at low temperatures. Both function can be reconciled if we increase the activation energy in Arrhenius law when temperature decreases (see Murrmann, 1973).

In these equations, $\sigma_{w}(\mathrm{~S} / \mathrm{m})$ is the pore water conductivity (which depends on salinity and temperature), $F$ (dimensionless) the intrinsic formation factor related to the porosity by the first Archie's law $F=\phi^{-m}$ where $m$ is called the first Archie exponent or porosity exponent (Archie, 1942), $\phi$ denotes the connected porosity (dimensionless), $\rho_{g}$ is the grain density $\left(\mathrm{kg} / \mathrm{m}^{3}\right.$, usually $\rho_{g} \approx 2,650 \mathrm{~kg} / \mathrm{m}^{3}$ ), and CEC is the cation exchange capacity $(\mathrm{C} / \mathrm{kg}$ and often expressed in meq/100 $\mathrm{g}$ with $1 \mathrm{meq} / 100 \mathrm{~g}=963.20 \mathrm{C} / \mathrm{kg})$. The product $F \phi$ corresponds to the bulk tortuosity of the pore space. The CEC is mainly sensitive of clay minerals. In equations (2) to (4), $B\left(\mathrm{~m}^{2} \cdot \mathrm{s}^{-1} \cdot \mathrm{V}^{-1}\right)$ denotes the apparent mobility of the counterions for surface conduction and $\lambda\left(\mathrm{m}^{2} \cdot \mathrm{s}^{-1} \cdot \mathrm{V}^{-1}\right)$ denotes the apparent mobility of the counterions for the polarization associated with the quadrature conductivity (Revil, Coperey, et al., 2017 and references therein). These apparent mobilities $B$ and $\lambda$ are close to the mobilities introduced by Waxman and Smits (1968) and Vinegar and Waxman

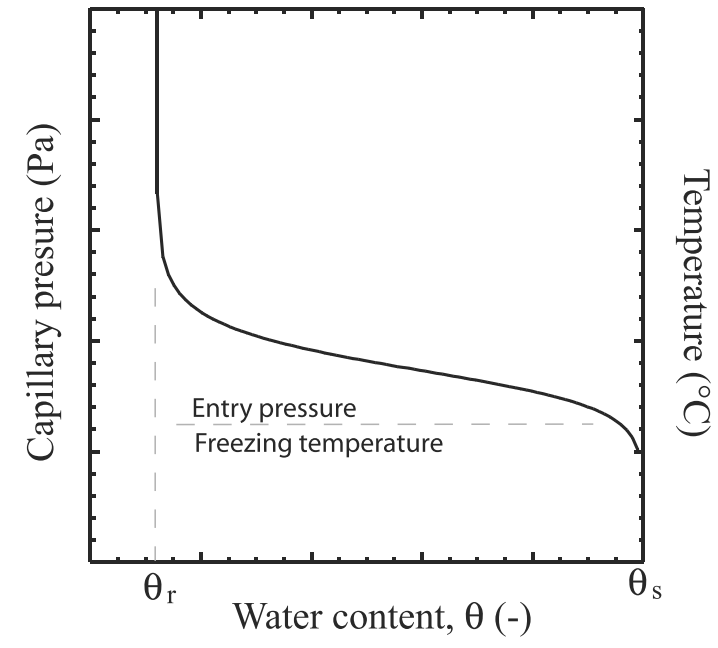

Figure 3. Sketch showing the analogy between the capillary pressure curve and the freezing curve neglecting hysteretic effects. The freezing temperature plays the same role as the capillary entry pressure in multiphase flow, both being related to the pore size. In both cases, the water content is comprised between the water content at saturation (given by the porosity $\theta_{S}=\phi$ ) and the residual water content at low saturations $\sigma\left(T_{0}=25^{\circ} \mathrm{C}\right)$. The residual water content may be related to the specific surface area of the material or its cation exchange capacity.
(1984), respectively. In the context of the dynamic Stern layer model, the apparent mobility $B$ is related to the intrinsic mobility of the counterions in the diffuse layer $\beta_{(+)}$and the mobility of the counterions in the Stern layer $\beta_{(+)}^{S}$ by $\left.B \equiv \beta_{(+)}(1-f)+\beta_{(+)}^{S} f\right)$ where $f$ (partition coefficient) denotes the fraction of the counterions of the electrical double layer contained in the Stern layer. The apparent mobility $\lambda=\beta_{(+)}^{S} f$ is related to the polarization process occurring only in the Stern layer.

A dimensionless number $R$ is also introduced by $R=\lambda / B$ (see Revil, Coperey, et al., 2017, for further explanations). From our previous studies (e.g., Ghorbani et al., 2018), we have $B\left(\mathrm{Na}^{+}, 25^{\circ} \mathrm{C}\right)=3.1 \pm 0.3 \times 10^{-9} \mathrm{~m}$ ${ }^{-2} \cdot \mathrm{s}^{-1} \cdot \mathrm{V}^{-1}$ and $\lambda\left(\mathrm{Na}^{+}, 25^{\circ} \mathrm{C}\right)=3.0 \pm 0.7 \times 10^{-10} \cdot \mathrm{m}^{-2} \cdot \mathrm{s}^{-1} \cdot \mathrm{V}^{-1}$, and $R$ is typically around $0.09 \pm 0.01$ (independent of both temperature and saturation). The dimensionless number $R$ appears to be the fundamental parameter to characterize polarization.

The two last terms of equations (2) and (3) correspond to the highfrequency and low-frequency surface conductivities given therefore by

$$
\begin{gathered}
\sigma_{S}^{\infty}=\left(\frac{1}{F \phi}\right) \rho_{g} B \mathrm{CEC}, \\
\sigma_{S}^{0}=\left(\frac{1}{F \phi}\right) \rho_{g}(B-\lambda) \mathrm{CEC} .
\end{gathered}
$$



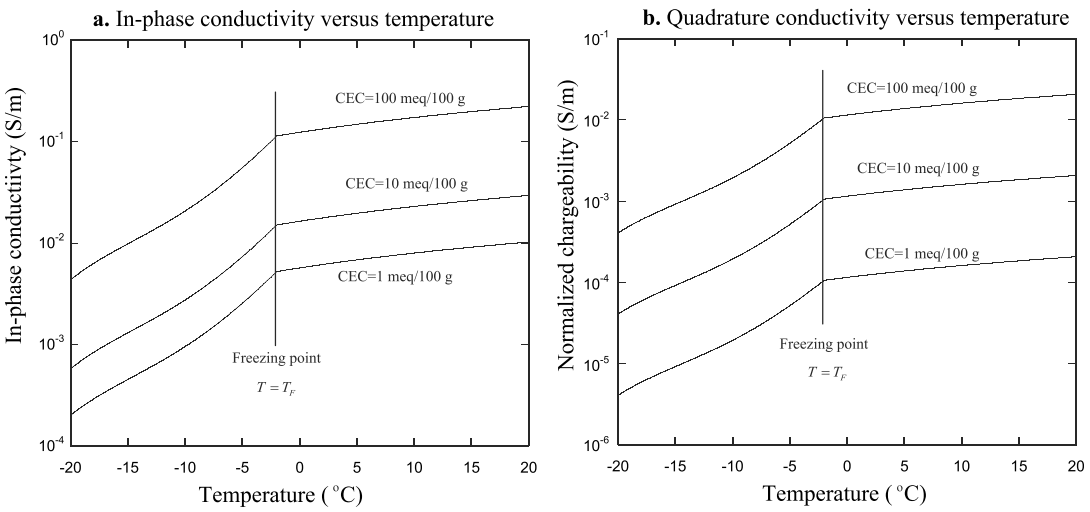

Figure 4. Sensitivity study of the in-phase conductivity and quadrature conductivity versus temperature for three different values of the cation exchange capacity using the freezing curve model corresponding to equation (16). (a) In-phase conductivity. (b) Quadrature conductivity. Values of the parameters used for the simulations: $B\left(\mathrm{Na}^{+}, 25^{\circ} \mathrm{C}\right)=3.1 \pm 0.3 \times$ $10^{-9} \mathrm{~m}^{-2} \cdot \mathrm{s}^{-1} \cdot \mathrm{V}^{-1}, \lambda\left(\mathrm{Na}^{+}, 25^{\circ} \mathrm{C}\right)=3.0 \pm 0.7 \times 10^{-10} \mathrm{~m}^{-2} \cdot \mathrm{s}^{-1} \cdot \mathrm{V}^{-1}, \phi=0.30, \sigma_{w}\left(\mathrm{NaCl}, 25^{\circ} \mathrm{C}\right)=0.1 \mathrm{~S} / \mathrm{m}, \varphi_{m}=0.25\left(\theta_{r}=\right.$ $\left.\phi-\varphi_{m}=0.05\right), T_{F}=-2{ }^{\circ} \mathrm{C}$, and $T_{C}=-4{ }^{\circ} \mathrm{C}$. In this exercise, a linear temperature dependence for the mobilities is used with $\alpha_{T}=0.02 /{ }^{\circ} \mathrm{C}$. The drop in electrical conductivity below the freezing point is due to the formation of ice.

From these relationships and definitions, it is also clear that the dimensionless number $R$ is also the ratio between the normalized chargeability and the high-frequency surface conductivity. Note that when surface conductivity dominates the conductivity response, we have

$$
\lim _{\sigma_{S}^{\infty}>>\sigma_{w}} \frac{M_{n}}{\sigma_{\infty}}=\frac{\lambda}{B}=R \approx 0.09 .
$$

In order to complete the unification of the induced polarization theory in terms of relationships between its fundamental parameters, Revil, Coperey, et al. (2017) developed a quantitative relationship between the normalized chargeability and the quadrature conductivity (see also Börner, 1992; Van Voorhis et al., 1973). This relationship is not based on the dynamic Stern layer model but on the causality principle that can be used to consistently model the in-phase and quadrature conductivities. Assuming that the distribution of the relaxation times $h(\tau)$ is broad enough, the following linear relationship can be derived between the quadrature conductivity (measured at the geometric mean of two frequencies $f_{1}$ and $f_{2}$ ) and the normalized chargeability defined as the difference between the in-phase conductivity at frequency $f_{2}>f_{1}$ and the in-phase conductivity at the frequency $f_{1}$ (see Appendix A in Revil, Coperey, et al., 2017)

$$
\sigma^{\prime \prime}\left(\sqrt{f_{1} f_{2}}\right) \approx-\frac{M_{n}\left(f_{1}, f_{2}\right)}{\alpha}=-\frac{\sigma^{\prime}\left(f_{2}\right)-\sigma^{\prime}\left(f_{1}\right)}{\alpha} .
$$

Table 1

Relevant Petrophysical of Parameters of the Sample

\begin{tabular}{llcccccc}
\hline Sample & \multicolumn{1}{c}{ Type } & Porosity, $\phi(-)$ & CEC $(\mathrm{meq} / 100 \mathrm{~g})$ & $Q_{V}\left(\mathrm{C} / \mathrm{m}^{3}\right)$ & $\theta_{r}(-)$ & Formation factor $F(-)$ \\
\hline AX & Clayey sand & 0.418 & 7.5 & $2.67 \mathrm{E}+07$ & 0.017 & 0.98 \\
CW & Clayey soil & 0.463 & 18.8 & $5.57 \mathrm{E}+07$ & 0.034 & 0.24 & 0.37 \\
ValT & Soil & 0.38 & 5.3 & $2.21 \mathrm{E}+07$ & 0.014 & 6.7 \\
ValT2 & Sandstone & 0.02 & 1.15 & $1.44 \mathrm{E}+08$ & 0.02 & 1434 \\
Sd184 & Fine sand & 0.387 & 0.096 & $3.88 \mathrm{E}+05$ & 0.0002 & 3.6 \\
S90M10 & Clayey sand & 0.47 & 4.2 & $1.21 \mathrm{E}+07$ & 0.008 & $3.56 \cdot 10^{-4}$ \\
M100 & montmorillonite & 0.90 & 41.9 & $1.19 \mathrm{E}+07$ & 0.007 & 0.0096 \\
COS & Granite & 0.028 & 0.80 & $7.09 \mathrm{E}+07$ & 0.028 & 0.091 \\
MON & Granite & 0.052 & 0.78 & $3.63 \mathrm{E}+07$ & 0.023 & 499 \\
\hline
\end{tabular}

Note. The formation factor and surface conductivity are determined with the pore water conductivities: 0.01, 0.1, 5.2, and 10.2 S/m for \#Val.T sample and 0.026, $0.08,0.9$, and $5.2 \mathrm{~S} / \mathrm{m}$ for \#COS and \#MON samples. $\phi$ denotes connected porosity (dimensionless), CEC is the cation exchange capacity in meq/100 $\mathrm{g}(=963.20$ $\mathrm{C} / \mathrm{kg}$ ), and $F$ and $\sigma_{S}$ denote the formation factor and the surface conductivity, respectively. For M100, the reported CEC is an average of two measurements. For Sd184, the CEC is an average of six measurements. The quantity $Q_{V}$ denotes the charge per unit pore volume (see Appendix A) and is computed from the connected porosity and the CEC. The residual water content $\theta_{r}$ is determined from equations (A4) and (A5) of Appendix A and the value of the CEC and porosity. 
Table 2

List of the Experiments Performed in the Present Study

\begin{tabular}{lccc}
\hline Experiment & Material & Temperature range $\left({ }^{\circ} \mathrm{C}\right)$ & $\sigma_{w}(\mathrm{~S} / \mathrm{m})$ \\
\hline$\# 1$ & AX & $+20 /-10$ & 0.8 \\
$\# 2$ & AX & $+20 /-15$ & 0.05 \\
$\# 3$ & CW & $+20 /-10$ & 0.8 \\
$\# 4$ & ValT & $+20 /-10$ & 0.01 \\
$\# 5$ & ValT & $+20 /-15$ & 0.1 \\
$\# 6$ & ValT & $+20 /-15$ & 1.0 \\
$\# 7$ & Sd184 & $+20 /-10$ & 0.01 \\
$\# 8$ & S90M10 & $+20 /-10$ & 0.01 \\
$\# 9$ & M100 & $+20 /-10$ & 0.01 \\
$\# 10$ & COS & $+20 /-15$ & 0.026 \\
$\# 11$ & MON & $+20 /-15$ & 0.026 \\
$\# 12$ & ValT2 & $+20 /-15$ & 0.019 \\
\hline
\end{tabular}

Note. The $\sigma_{w}$ denotes pore water salinity at $25^{\circ} \mathrm{C}$. For the Experiments 1 to 4 and 5 to 9 , we used $\mathrm{NaCl}$ solutions, whereas for the Experiments 4, 10, and 11 , the samples were saturated with fresh water from the same sites of the samples.

The value of $\alpha$ is determined using Drakes's model also called the constant phase model (see Börner, 1992; Van Voorhis et al., 1973, for some in-depth analysis of this model) and is given by

$$
\alpha \approx \frac{2}{\pi} \ln \left(10^{A}\right),
$$

where $A$ is the number of decades separating high and low frequencies, for example, for two decades $f_{2}=100 f_{1}, A=2$ (see Revil, Coperey, et al., 2017, for details). Typically, $\alpha$ is on the order of 8-9 if we consider very low and very high frequencies used to define $M_{n}=\sigma_{\infty}-\sigma_{0}$ (e.g., $10 \mathrm{mHz}$ and 10 kHz; e.g., Revil, Coperey, Deng, et al., 2018, $A=6$ and $\alpha \approx 8.8$ ). If $\alpha$ is determined over two decades only (as done below between $10^{-2}$ and $1 \mathrm{~Hz}$, i.e., $\alpha=2.9$ ), it is therefore enough to use a correction factor of $\sim 3$ to determine in this situation the normalized chargeability that would be obtained by $M_{n}=\sigma_{\infty}-\sigma_{0}$.

We discuss now the temperature dependence of the complex conductivity above the freezing temperature (typically but not necessarily around 0 $\left.{ }^{\circ} \mathrm{C}\right)$. Following Vinegar and Waxman (1984) and Revil, Coperey, et al. (2017), the pore water conductivity and mobilities $B$ and $\lambda$ have all the following linear temperature dependence

$$
\Theta(T)=\Theta\left(T_{0}\right)\left[1+\alpha_{T}\left(T-T_{0}\right)\right]
$$

where $T_{0}$ and $T$ are the reference temperature $\left(T_{0}=25^{\circ} \mathrm{C}\right)$ and the temperature $\left({ }^{\circ} \mathrm{C}\right)$; respectively, $\Theta(T)$ corresponds to $\sigma_{w}(T), B(T)$, or $\lambda(T)$ and $\Theta\left(T_{0}\right)$ corresponds to the same property at $T_{0}$; and the sensitivity $\alpha_{T}$ is in the range $0.019-0.022 /{ }^{\circ} \mathrm{C}$ (e.g., Revil, Coperey, et al., 2017). According to equation A10 of Appendix A, the conductivity goes to zero at a temperature of $-25^{\circ} \mathrm{C}$, remarkably close to the so-called eutectic temperature

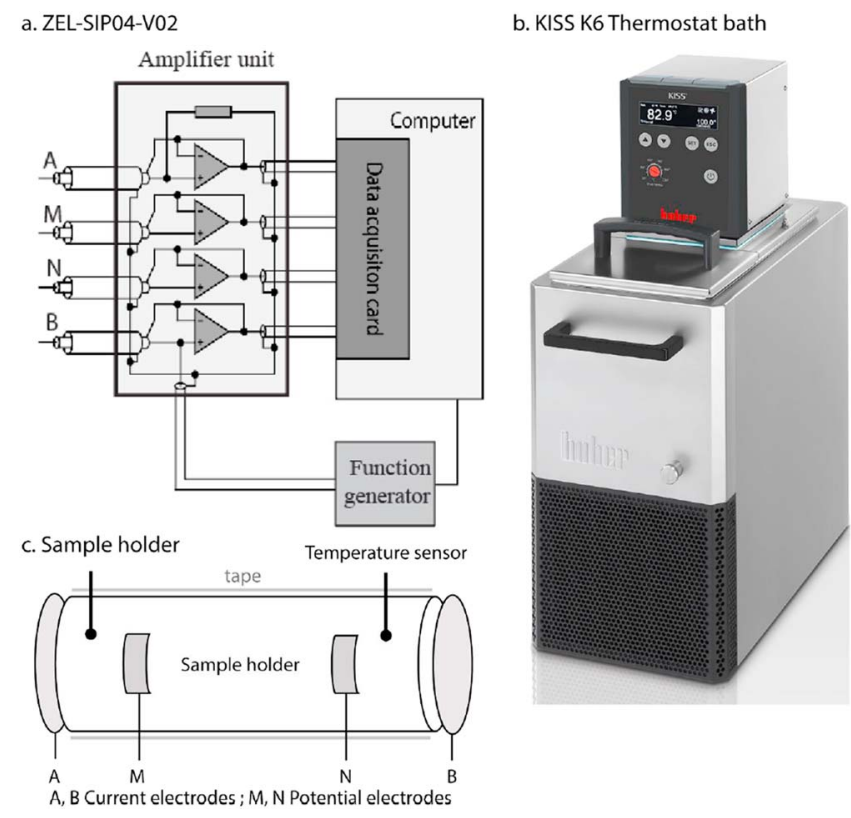

Figure 5. Equipment and sample holder. (a) Impendence meter ZELSIP04-V02 used for complex conductivity meter (see Zimmermann et al., 2008). (b) Thermostat bath KISS K6. Dimensions $210 \times 400 \times 546 \mathrm{~mm}$, bath volume 4.5 L. (c) Sample holder for unconsolidated sample. Sample placed in centrifuged tub (diameter of $\sim 2.5 \mathrm{~cm}$, height of $9.0 \mathrm{~cm}$ ). Film carbon electrodes are used for the ABMN electrodes.
$T_{E}$ close to $-21^{\circ} \mathrm{C}$ for $\mathrm{NaCl}$. Actually, the eutectic temperature is exactly predicted for $\alpha_{T}=1 /\left(T_{E}+T_{0}\right)=0.0217 /{ }^{\circ} \mathrm{C}$. Reaching the eutectic temperature leads to the simultaneous crystallization of ice and salt. In equation (10), the temperature dependence of the pore water conductivity is controlled by the temperature dependence of the ionic mobilities of the cations and anions. Taking equations (8) to (10) into equations (1) to (4), the temperature dependence of the complex conductivity (i.e., inphase and quadrature conductivities) is therefore imposed by the thermal dependence of charge carrier mobilities.

An alternative expression in equation (10) is to use Arrhenius law (Ghorbani et al., 2018; Revil, Coperey, Mao, et al., 2018)

$$
\Theta(T)=\Theta\left(T_{0}\right) \exp \left[-\frac{E_{a}}{k_{b} N}\left(\frac{1}{T}-\frac{1}{T_{0}}\right)\right],
$$

where $T$ and $T_{0}$ are expressed here in degree Kelvin (K; $T_{0}=298 \mathrm{~K}$, i.e., 25 ${ }^{\circ} \mathrm{C}$ ), $k_{b} N=8.314 \mathrm{~J} \cdot \mathrm{mol}^{-1} \cdot \mathrm{K}^{-1}$ (gas constant), $\Theta(T)$ and $\Theta\left(T_{0}\right)$ denotes the corresponding property at temperatures $T$ and $T_{0}$, respectively, and $E_{a}$ is typically on the order of $16 \mathrm{~kJ} / \mathrm{Mol}$ above $20{ }^{\circ} \mathrm{C}$ (e.g., Ghorbani et al., 2018). Murrmann (1973) found an activation energy of $18 \mathrm{~kJ} / \mathrm{Mol}$ for the temperature range $15-20{ }^{\circ} \mathrm{C}, 22 \mathrm{~kJ} / \mathrm{Mol}$ for the temperature range 0 to $-4{ }^{\circ} \mathrm{C}$ and up to $40 \mathrm{~kJ} / \mathrm{Mol}$ for the temperature range -10 to $-15^{\circ} \mathrm{C}$.

The first point we address in this paper is to choose between equations (10) and (11). A comparison between the two expressions is shown in Figure 2. Usually in the temperature range comprised between the freezing temperature $\left(-5^{\circ} \mathrm{C}\right.$ in the case shown in Figure 2$)$ and $25^{\circ} \mathrm{C}$, both equation 


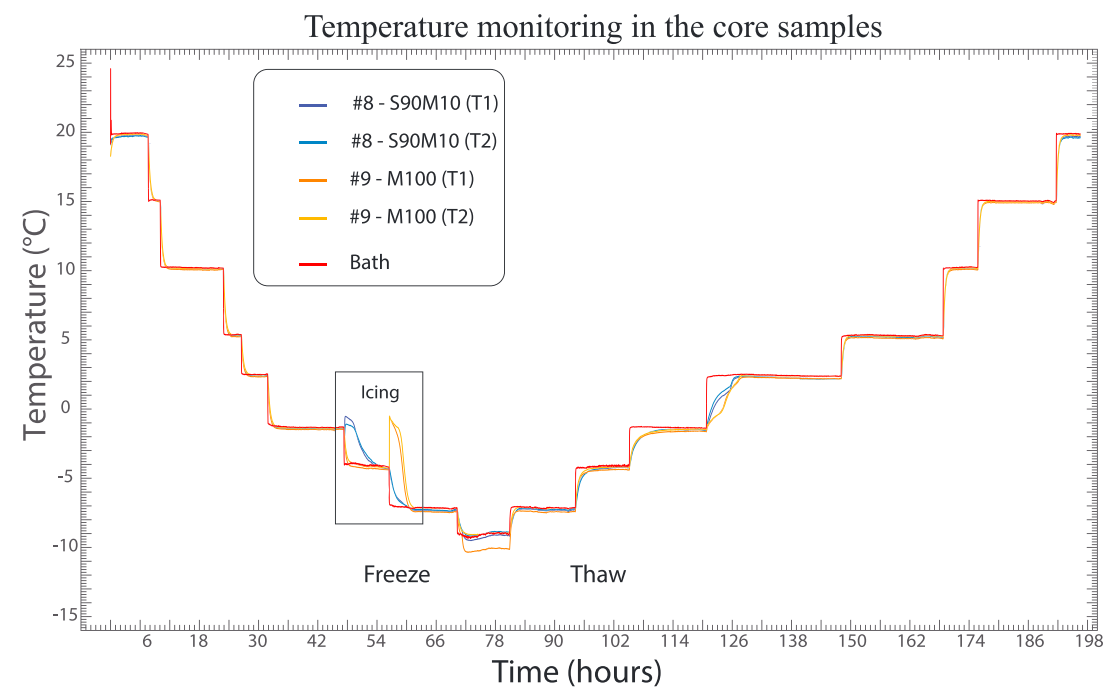

Figure 6. Temperature monitoring for Experiments $\# 8$ and $\# 9$ with samples $\mathrm{S} 90 \mathrm{M} 10$ and $\mathrm{M} 100\left(\sigma_{w}=0.01 \mathrm{~S} / \mathrm{m}\right)$. We show temperatures from the two temperature sensors (called T1 and T2) for the each sample. Temperature levels are 20, 15, 10, $5,2,-2,-5,-8$, and $-10^{\circ} \mathrm{C}$. The peaks in the box named icing can be explained by the latent heat during freezing, which corresponds to an exothermic reaction. The $90 \%$ of sand sample start to freeze at a higher temperature by comparison with clay-rich materials, which freeze between -5 and $-8{ }^{\circ} \mathrm{C}$. The complex conductivity measurements are done once the sample has reached thermal equilibrium to minimize the effect of supercooling.

fit the data equally well. However, equation (10) does not require adapting the sensitivity coefficient $\alpha_{T}$ with the temperature to predict the eutectic temperature (at which conductivity would reach zero) while equation (11) would require an adjustment of the activation energy with the temperature.

\subsection{Extension of the Dynamic Stern Layer Model in Freezing Conditions}

In freezing conditions, we need also to model the effect of the phase change corresponding to the transformation between liquid water and ice in the connected pore space. Another complication is related to the seg-

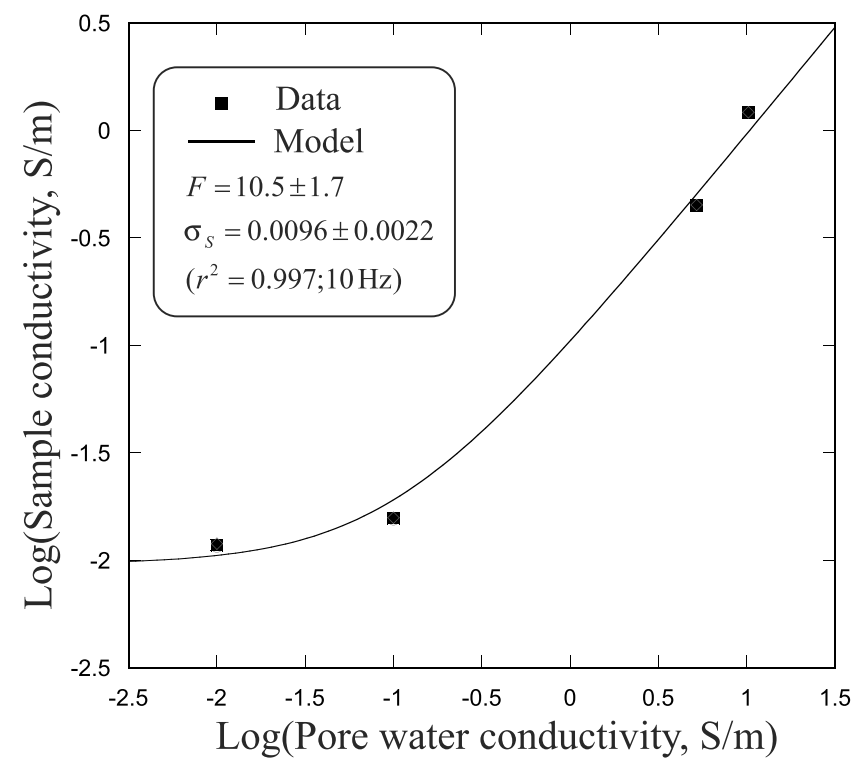

Figure 7. Determination of the formation factor and surface conductivity at room temperature $\left(20^{\circ} \mathrm{C}\right)$ using the conductivity of the sample plotted as a function of the conductivity of the pore water $(\mathrm{NaCl}$, different salinities; see Table 2). The plain line corresponds to equation (21). Sample ValT at room temperature $\left(\sim 20^{\circ} \mathrm{C}\right)$. regation of the salt between the liquid pore water and the ice. We will assume that the salt remains preferentially in the liquid water phase, and therefore, the conductivity of the pore water should be replaced by $\sigma_{w} \phi / \theta$, where $\theta$ denotes the water content (dimensionless) and $\sigma_{w}$ is the pore water conductivity at saturation (and therefore at the initial salinity) with the brine used for saturating the porous material. Indeed, the solubility of salts in ice is extremely low if not negligible (Hobbs, 2010). Only for temperatures lower than the eutectic temperature (approximately $-21^{\circ} \mathrm{C}$ for $\mathrm{NaCl}$ ), the ions can be trapped in the ice and complete freezing for the system $\mathrm{NaCl} /$ water is achieved.

Equations (2) to (4) need to show explicitly the dependence of the different properties with the water content. Assuming that the first and second Archie exponents are equal to each other, that is, $n=m$ (see Revil, 2013a) and assuming the segregation of the salt in the liquid water phase, these equations can be written as

$$
\begin{gathered}
\sigma_{\infty}=\theta^{m-1}\left(\phi \sigma_{w}+\rho_{g} B \mathrm{CEC}\right), \\
\sigma_{0}=\theta^{m-1}\left[\phi \sigma_{w}+\rho_{g}(B-\lambda) \mathrm{CEC}\right], \\
M_{n}=\theta^{m-1} \rho_{g} \lambda \mathrm{CEC}
\end{gathered}
$$

Note that these equations are also valid above the freezing temperature for sample at partial or full saturation. In this last case (full saturated 

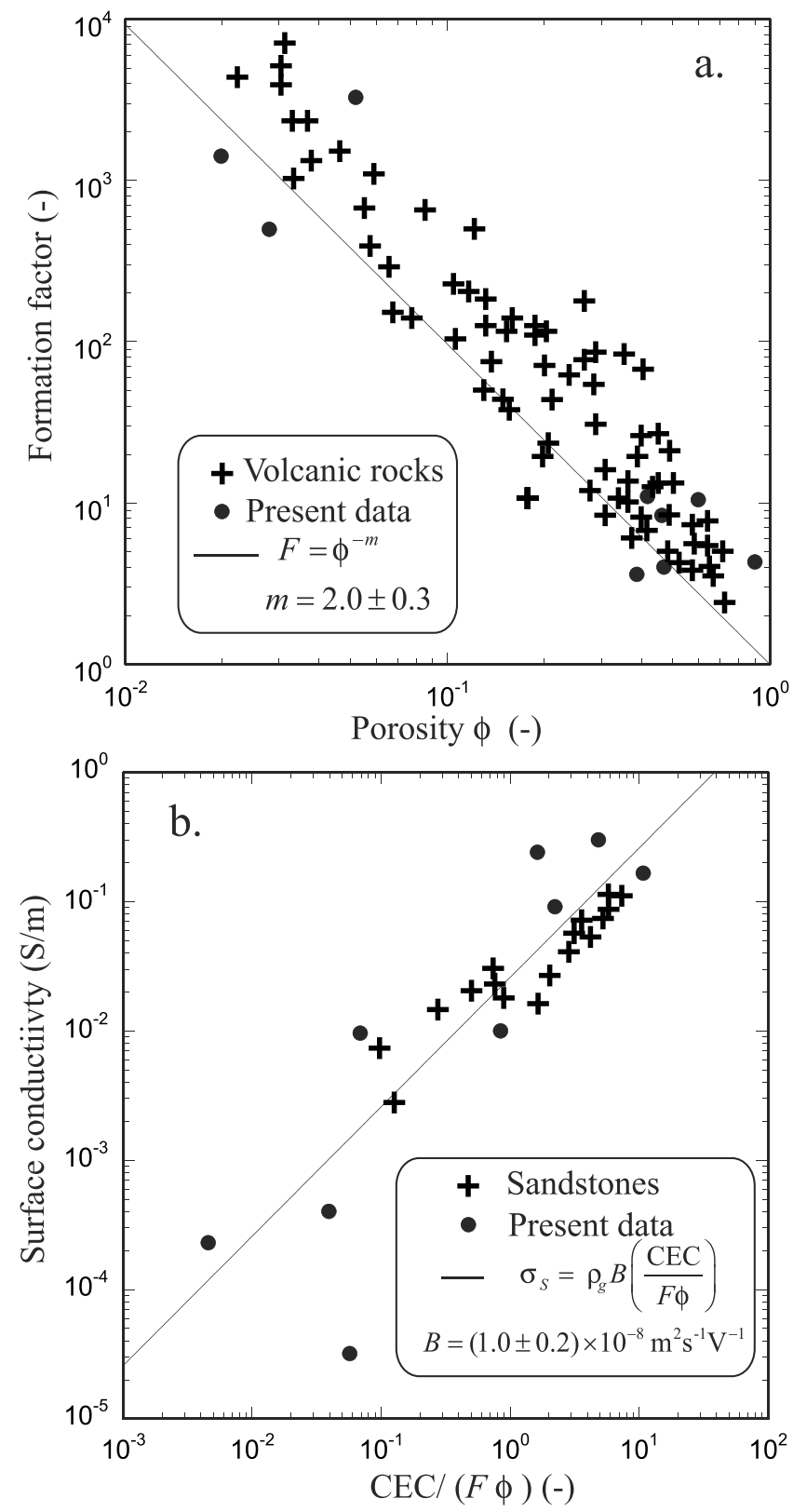

Figure 8. Analysis of the formation factor and surface conductivity. (a) Formation factor versus porosity used to check Archie's law, which is used to determine the porosity exponent $m$. The data are contrasted with the data from Ghorbani et al. (2018) using volcanic rocks showing that the data obey a power law relationship called Archie's law (Archie, 1942). (b) Surface conductivity versus the normalized CEC (i.e., corresponding to the ratio $\mathrm{CEC} / F \phi)$. The linear trend is used to determine the value of the mobility of the counterions in surface conductivity $B$. The fits (plain lines) are performed only on our data. For comparison, we also added tight sandstone data from the study performed by Revil, Coperey, Deng, et al. (2018). CEC $=$ cation exchange capacity. medium), porosity $\phi$ can be replaced by water content $\theta$ in these equations, while being consistent with equations (2)-(4). Below freezing conditions, the water content of the liquid water changes with the temperature according to a freezing curve (e.g., Amiri et al., 2018) also called in the literature the phase composition curve (unfrozen water content as a function of temperature). These freezing curves are typically assessed through nuclear magnetic (Nuclear Magnetic Resonance, NMR) measurements in freezing conditions (e.g., Watanabe \& Mizoguchi, 2002). One freezing curve corresponds to the Gaussian soil freezing curve developed by McKenzie et al. (2007) and Amiri et al. (2018, their equation (14))

$$
\theta(T)=\left\{\begin{array}{l}
\left(\phi-\theta_{r}\right) \exp \left[-\left(\frac{T-T_{F}}{T_{C}}\right)^{2}\right] \\
\phi, \quad \theta_{r}, T \leq T_{F}
\end{array},\right.
$$

which has the advantage to require only three parameters, $T_{F}$ (the liquidus or freezing point), $T_{C}$ (a fitting parameter called a characteristic temperature similar to a characteristic time in relaxation phenomena), and $\theta_{r}$ the residual water content. In this equation, $\varphi_{m}=\phi-\theta_{r}$ denotes the maximum volumetric ice content at low temperatures but still above the eutectic point. The effect of salt concentration upon the freezing temperature $T_{F}$ can be determined from the empirical equation proposed by Potter et al. (1978).

The residual water content is dependent on the physicochemical properties of the soil such as specific surface area and surface charge density (e.g., Anderson \& Tice, 1972). This relationship supports the hypothesis that the residual water content is formed essentially by a sorbed water film (bound water) at the interface between the ice and the surface of the mineral grains (Dash et al., 1995). Since the surface charge density of soils and porous media is rather constant and since the specific surface area is proportional to the $\mathrm{CEC}$, we postulate that there should be a relationship between the residual water content and the CEC. The physics of this relationship is explored in details in Appendix A.

Equation (15) is chosen in such a way it provides a fully liquid watersaturated material at $T=T_{F}$ (for a low salinity pore water) and a residual pore water at low temperatures (typically below $-10{ }^{\circ} \mathrm{C}$ ). The residual pore water disappears at the eutectic temperature. According to McKenzie et al. (2007), the freezing curve could be seen as an analogy to the capillary pressure curve (see Figure 3). In this case, we could use popular models developed to model the capillary pressure curve such as the Brooks and Corey model or the van Genuchten model (Brooks \& Corey, 1964; Van Genuchten, 1980). As a matter of fact such power law has indeed been used in the literature as a freezing curve.

In Duvillard et al. (2018), we used an exponential function that provides a smoother transition (by comparison with the Gaussian or the Brooks and Corey models) between the unfrozen and frozen states and gives a better fit of the data. This function, quite similar to Equation (15), is given by

$\theta(T)=\left\{\begin{array}{l}\left(\phi-\theta_{r}\right) \exp \left(-\frac{T-T_{F}}{T_{C}}\right)+\theta_{r}, T \leq T_{F} \\ \phi,\end{array}\right.$. 

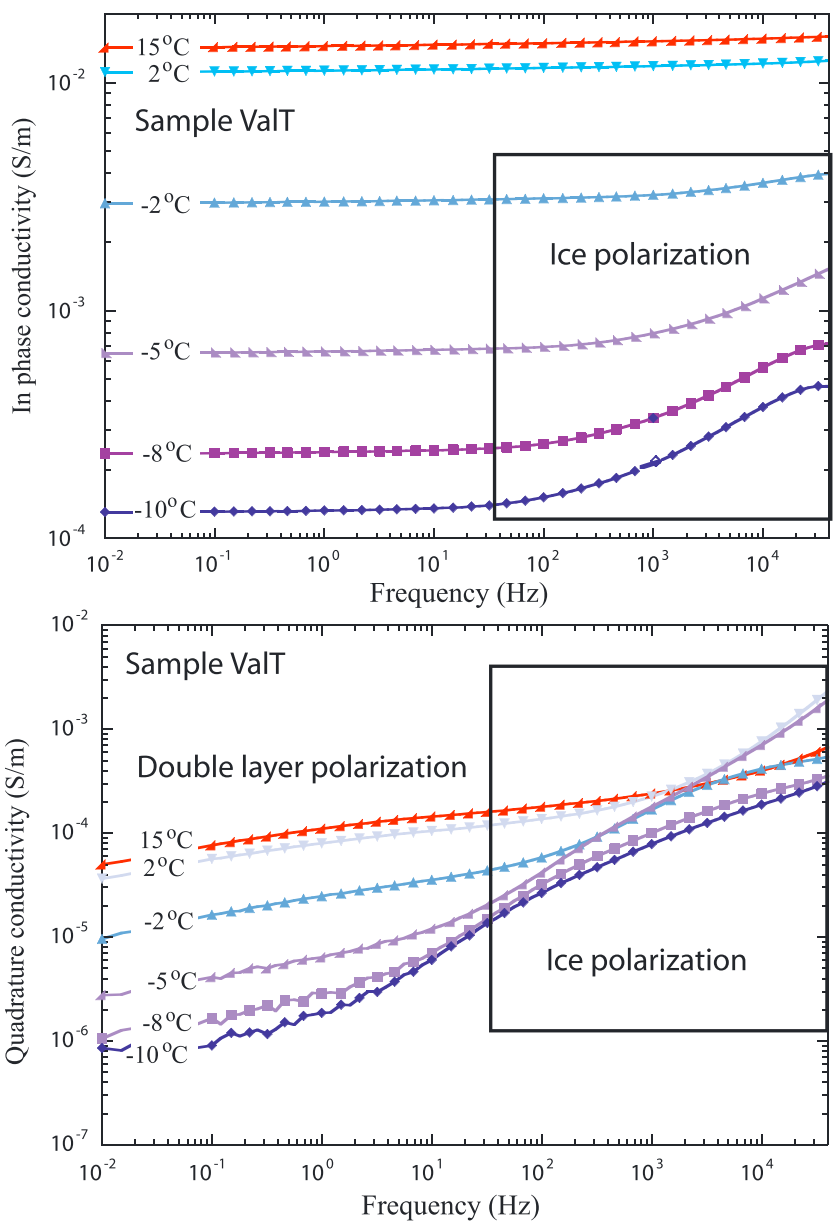

Figure 9. Complex conductivity spectra (in-phase and quadrature conductivity) at different equilibrium temperatures during freezing. Sample ValT, frequency range $10^{-2} \mathrm{~Hz}$ to $40 \mathrm{kHz}$. The data correspond to Experiment \#4 (pore water conductivity at $25^{\circ} \mathrm{C}$, snowmelt, $0.01 \mathrm{~S} / \mathrm{m}$ ). The plain lines are just guides for the eyes.
We call this function the exponential freezing curve function below. With the previous assumptions and assuming furthermore that $m$ is close to 2 (as checked below), the electrical conductivities and normalized chargeability are given from equations (12) to (14) by

$$
\begin{gathered}
\sigma_{\infty}=\theta(T)\left[\phi \sigma_{w}(T)+\rho_{g} B(T) \mathrm{CEC}\right], \\
\sigma_{0}=\theta(T)\left\{\phi \sigma_{w}(T)+\rho_{g}[B(T)-\lambda(T)] \mathrm{CEC}\right\}, \\
M_{n}=\theta(T) \rho_{g} \lambda(T) \mathrm{CEC},
\end{gathered}
$$

and a similar equation can be obtained for the quadrature conductivity,

$$
\sigma^{\prime \prime}=-\theta(T) \frac{\rho_{g} \lambda(T)}{\alpha} \mathrm{CEC},
$$

where $\alpha$ is on the order of 8-9 (see section 2.1. above). In this model, we do not account for another polarization mechanism associated with the polarization of the ice itself. We will show later that the polarization of ice may actually happen but at higher frequencies (above 10-100 Hz, for more details about the polarization or dielectric characteristics of ice; Buchanan et al., 2011; Ingham et al., 2012; O'Sadnick et al., 2016).

Figure 4 shows the type of curve expected for different values of the CEC of the material. Note the break in the slope of the trends through the freezing temperature. We will see later that experimental data exhibit such behaviors.

\section{Material and Methods}

\subsection{Samples and Experiments}

We selected nine samples of different lithologies including soils and hard rocks in order to characterize the dependence of their complex conductivity with respect to temperature. Samples AX and CW are two soils from the Walcheren peninsula (Netherlands). Sample AX is a fine sand, while CW is very clayey soil (both described in Revil, Coperey, et al., 2017, at room temperature). Sd184 denotes a pure silica sand with a unimodal grain size distribution (mean grain diameter of $184 \mu \mathrm{m}$, measured by wet Malvern laser scattering). Sample M100 corresponds to a green montmorillonite. Sample S90M10 is a mix of $90 \%$ (wt.) of pure silica sand (\#Sd184) and 10\%(wt.) of green montmorillonite (\#M100). Sample ValtT corresponds to a soil from Thorens rock glacier (Vanoise massif) in the French Alps. Sample ValT2 is a metamorphized sandstone containing graphite from the same site. Samples COS (granite) and MON (metamorphic granite) are relatively fresh hard rock samples collected at Refuge des Cosmiques and Aiguille des Grands Montets, respectively, in the Mont Blanc massif in the French Alps. The main petrophysical characteristics of these samples are summarized in Table 1.

A total of 12 experiments was performed using different pore water conductivities: $\sigma_{w}\left(25^{\circ} \mathrm{C}\right)=0.01,0.026$, $0.05,0.1,0.8,1.0 \mathrm{~S} / \mathrm{m}$ (see details in Table 2). Experiments 4, 10, and 11 were done with water from snow melt collected on the massif of the core sample in the French Alps. For Experiments 1 to 3 and 5 to 9, we prepared $\mathrm{NaCl}$ brine solutions (adding dry $\mathrm{NaCl}$ salt to demineralized water). Experiments 1, 2, and 4 to 6 were done at different water conductivities in order to identify its impact of salinity upon induced polarization measurements and on phase change.

\subsection{Complex Conductivity Measurements Versus Temperature}

The samples were first dried during $24 \mathrm{hr}$ at about $50^{\circ} \mathrm{C}$ and then saturated under vacuum with the solutions (see Woodruff et al., 2014, for a detail of this procedure). The samples were left at least 1 month in the solution in order to reach complete equilibrium. The water conductivity was measured regularly until stabilized 

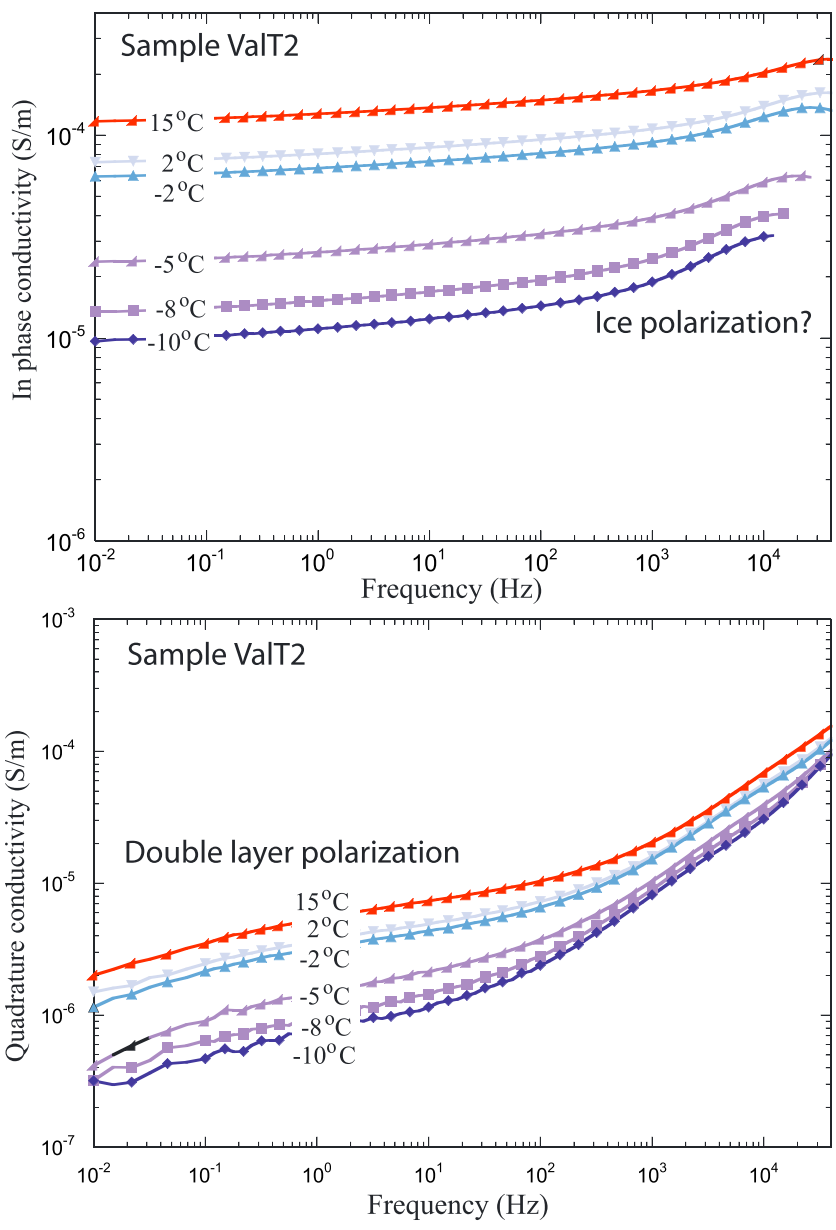

Figure 10. Complex conductivity spectra (in-phase and quadrature conductivity) at different equilibrium temperatures during freezing. Sample ValT2, frequency range $10^{-2} \mathrm{~Hz}$ to $40 \mathrm{kHz}$. The plain lines are just guides for the eyes. This data set corresponds to Experiment \#12 (pore water conductivity at $\left.25^{\circ} \mathrm{C}, \mathrm{NaCl}, 0.019 \mathrm{~S} / \mathrm{m}\right)$. values were reached. For Experiments 1, 2, and 4 to 6 (performed with different pore water salinities; see Table 2), the change of salinity used was realized by diffusion over several weeks.

Complex conductivity measurements were performed with the four electrodes method, that is, separating the current electrodes (A and B) and the potential electrodes ( $M$ and N; see Figure 5). For the experiments with soil or sand clay mixes, we put each sample in a tube whose diameter is 2.5 $\mathrm{cm}$ and height is $9 \mathrm{~cm}$ (see Figure 5). The two potential electrodes $\mathrm{M}$ and $\mathrm{N}$ are localized on the surface of the tube and are separated by a distance of $\sim 5 \mathrm{~cm}$. At the end faces of the tube, we place the two current electrodes A and B. The electrodes and samples are sealed to avoid pore water leaks during the course of the experiment. In our experiment, we impose the difference of voltage between electrodes A and B and the instrument can drive very small current to cross the core sample. Regarding the voltage electrodes $\mathrm{M}$ and $\mathrm{N}$, it is important to consider that the input impedance of the voltmeter used to measure the difference of voltage between these two electrodes should be always 10 times higher than the impedance of the core sample between the two electrodes. We checked that this is always the case here.

For the three rocks COS, MON, and ValT2, the potential electrodes are attached on the external sides of the cubic samples. This side is covered with insulating tape except at the position of the electrodes $\mathrm{M}$ and $\mathrm{N}$ where two small windows allow the electrodes to physically contact the rock. The current electrodes A and B are fixed at the end faces of the core sample (see Ghorbani et al., 2018, for details). We use medical film carbon electrodes because (i) their contact resistance is low, that is, less than 10 $\mathrm{k} \Omega$, (ii) we checked that they are electrically and chemically stable over the duration of the experiments (several weeks), and (iii) the film does not deteriorate when the freezing point is reached and at lower temperatures. We tested some $\mathrm{Ag} / \mathrm{AgCl}_{2}$ electrodes, but after few days, their contact resistance goes up and the film physically and chemically deteriorates during the course of the experiments.
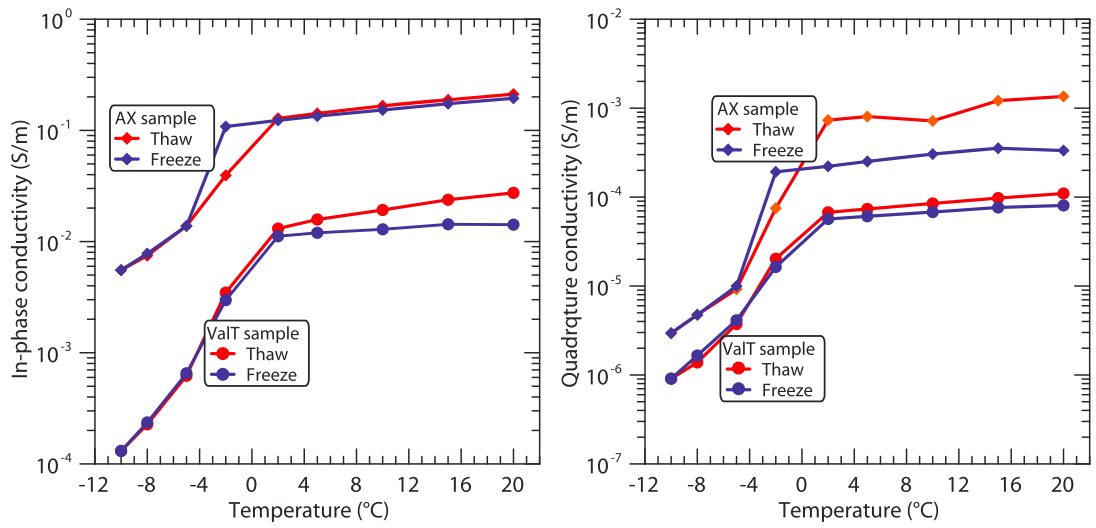

Figure 11. Hysteresic phenomena for Experiments \#1 (sample AX) and \#4 (sample ValT) during freeze and thaw. We start the measurements at $20^{\circ} \mathrm{C}$ and then we decrease the temperature down to the lowest temperature. Then we go up to the started temperature again. The in-phase and the quadrature conductivity are here reported at $1 \mathrm{~Hz}$ for samples $\operatorname{AX}\left(\sigma_{w}=0.8 \mathrm{~S} / \mathrm{m}\right)$ and ValT $\left(\sigma_{w}=0.01 \mathrm{~S} / \mathrm{m}\right)$ during freeze and thaw. Experiment \#4 exhibits weak hysteresis, while Experiment \#1 exhibits a stronger hysteretic behavior. This phenomenon can be explained by a change in the microstructure of the core sample. 


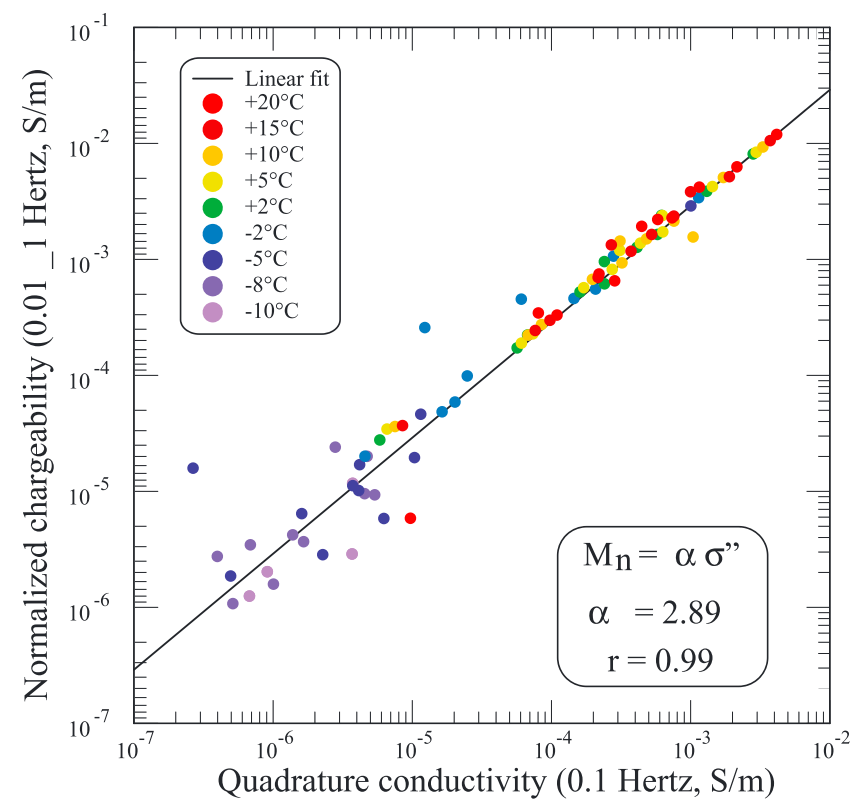

Figure 12. Comparison between the normalized chargeability (here defined as the difference of the in-phase conductivity between two frequencies $10^{-2}$ and $1.0 \mathrm{~Hz}$ ) and the quadrature conductivity at the geometric mean frequency $(0.1 \mathrm{~Hz})$. The scatter observed in the data at low temperature is due to the increased difficulty in measuring a smaller polarization when temperature decreases.
Complex conductivity measurements are carried out with a high precision impedance analyzer ZEL-SIP04-V02, built by Zimmermann et al. (2008; see Figure 5). Resistance and phase shift are measured in the frequency range of 0.01 to $45 \mathrm{kHz}$. Precision on phase shift is $\sim 0.1-0.2 \mathrm{mrad}$ below $1 \mathrm{kHz}$ (see Woodruff et al., 2014, for some benchmarks). The acquisition of a complete spectrum (at one temperature) takes approximately 20 min using two periods for each frequency. Besides, the measurements at $1 \mathrm{~Hz}$ are regularly repeated during the acquisition in order to check the (thermal) stability of the sample and the repeatability of the measurements. The impedance is converted to the complex conductivity components using a geometrical factor $K\left(\mathrm{~m}^{-1}\right)$. Geometrical factor depends of the geometry of the electrodes and boundary conditions for the cylindrical and cubic core samples and expressed by $K=L / A$ where $A\left(\mathrm{~m}^{2}\right)$ denotes the surface area of the current electrodes and $L(\mathrm{~m})$ the distance between the potential electrodes $\mathrm{M}$ and $\mathrm{N}$.

The samples were put in a bag and immersed in a thermally controlled bath (Kiss K6 from Huber; see Figure 5). The temperature of the bath is regulated with a precision of $0.1{ }^{\circ} \mathrm{C}$ and the heat carrying fluid in the tank is monoethylene glycol. We performed complex conductivity measurements before and after putting the sample in the thermal bath in order to be sure that there was no electrical short circuit or leak in the bag and that the thermal bath did not affect the measurements. Most of the measurements were done at an imposed voltage of 1.0 volt between electrodes $\mathrm{A}$ and $\mathrm{B}$ for unconsolidated samples and 0.5 volts for the hard rocks.

We investigate the complex conductivity spectra over the temperature range of $+20^{\circ} \mathrm{C}$ to $-10{ }^{\circ} \mathrm{C}$ to $-15^{\circ} \mathrm{C}$ (see Table 2 and Figure 6). In order to characterize hysteresis, measurements were made from positive to negative temperatures and then from negative to positive temperatures (see Figure 6). A complete
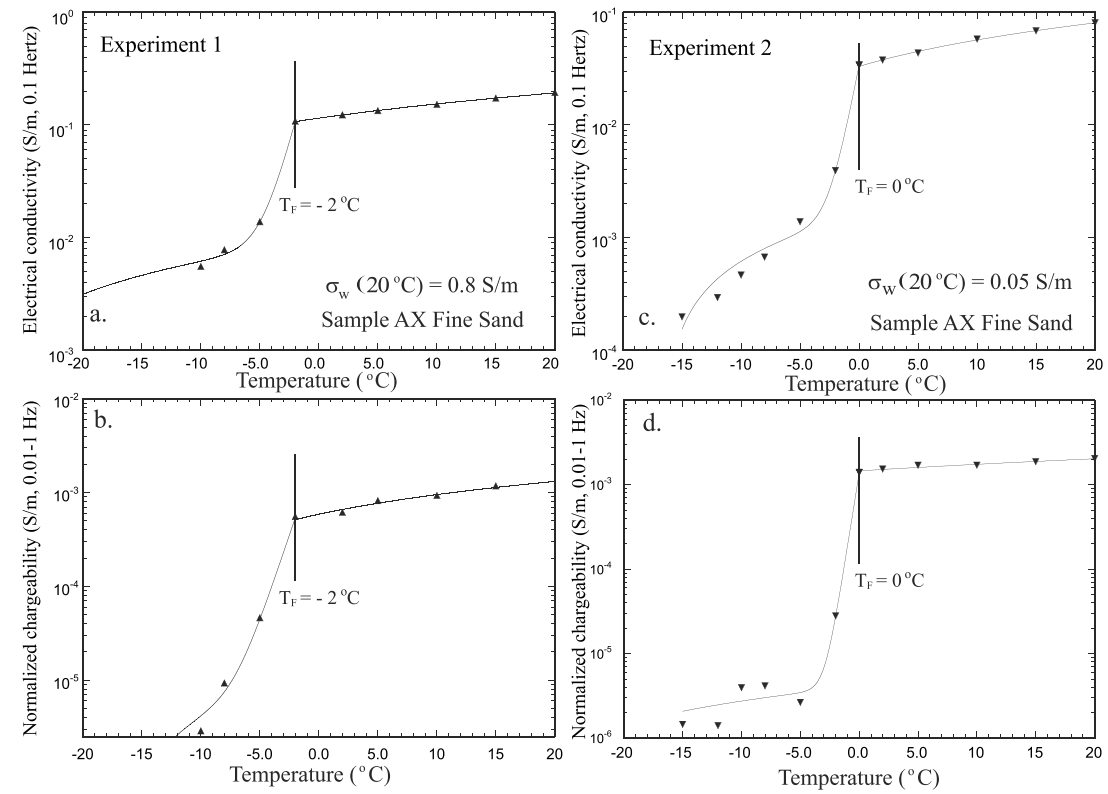

Figure 13. Evolution of the conductivity and normalized chargeability as a function of the temperature. (a) Experiment 1. Electrical conductivity (soil freezing curve, equation (16)). (b) Experiment 1. Normalized chargeability (soil freezing curve, equation (16)). Evolution of the conductivity and normalized chargeability as a function of the temperature. (c) Experiment 2. Electrical conductivity (soil freezing curve, equation (16)). (d) Normalized chargeability (soil freezing curve, equation 16). 

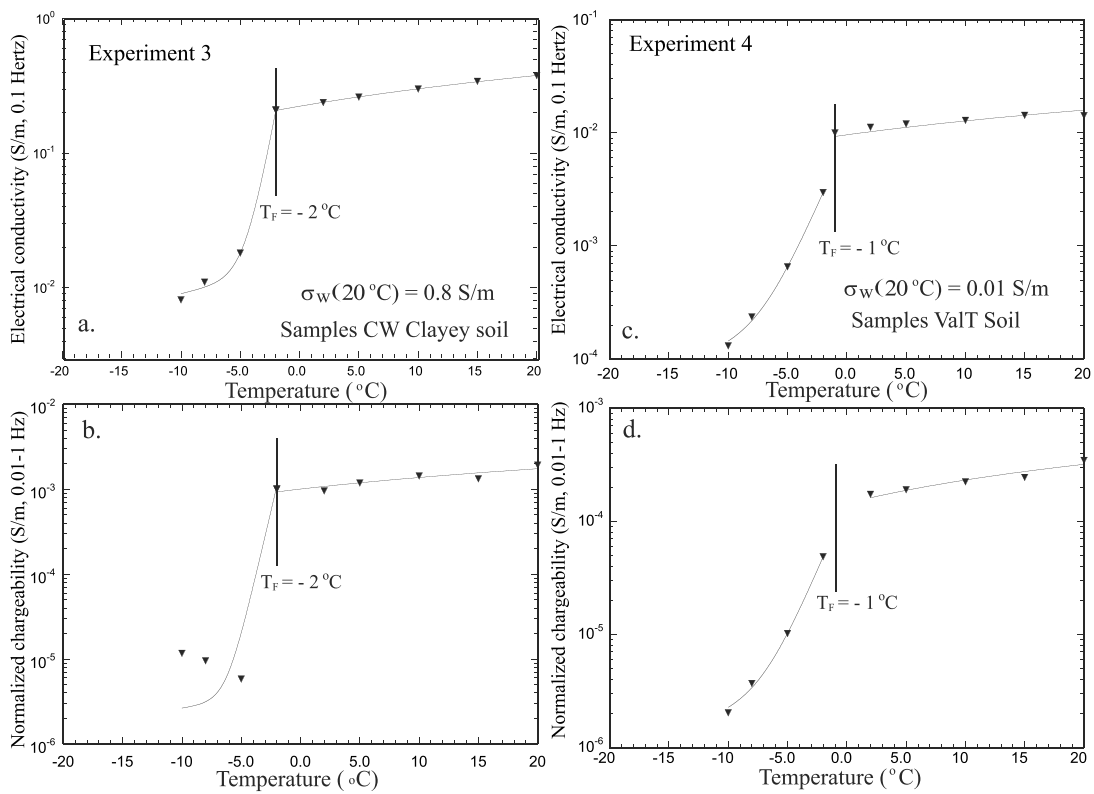

Figure 14. Evolution of the conductivity and normalized chargeability as a function of the temperature. (a) Experiment 3 . Electrical conductivity (soil freezing curve, equation (16)). (b) Experiment 3. Normalized chargeability (soil freezing curve, equation (16)). (c) Experiment 4. Electrical conductivity (soil freezing curve, equation (16)). (d) Experiment 4. Normalized chargeability (soil freezing curve, equation (16)).

experiment takes about $200 \mathrm{hr}$. At each level of temperature, we let enough time (several hours) for the temperature of the sample to stabilize. We check thermal state of sample thanks to temperature sensors (see Figure 6). For each experiment, sample and bath temperatures were recorded every minute with varnish thermocouples in contact with the core sample and one sensor in the bath. We use $\mathrm{K}$ thermocouples and a data logger CR1000 from Campbell scientific. The accuracy of the absolute temperature measurement
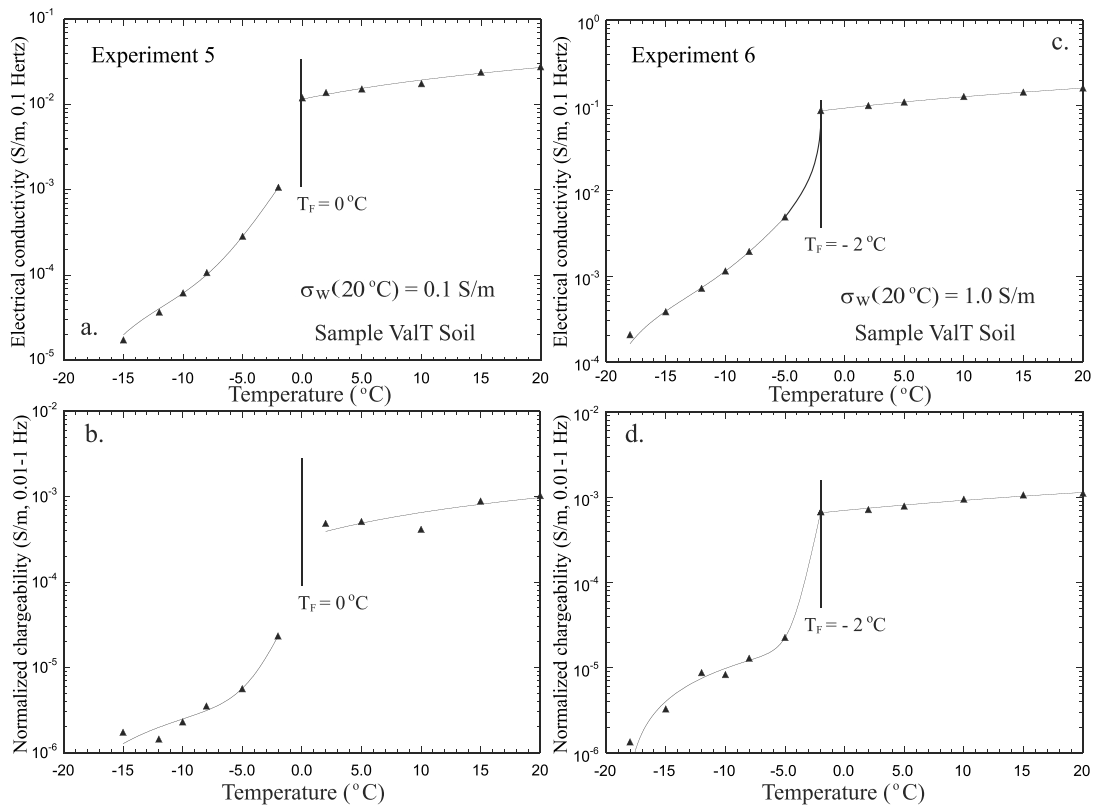

Figure 15. Evolution of the conductivity and normalized chargeability as a function of the temperature. (a) Experiment 5. Electrical conductivity (soil freezing curve, equation (16)). (b) Experiment 5. Normalized chargeability (soil freezing curve, equation (16)). (c) Experiment 6. Electrical conductivity (soil freezing curve, equation (16)). (d) Experiment 6. Normalized chargeability (soil freezing curve, equation (16)). 

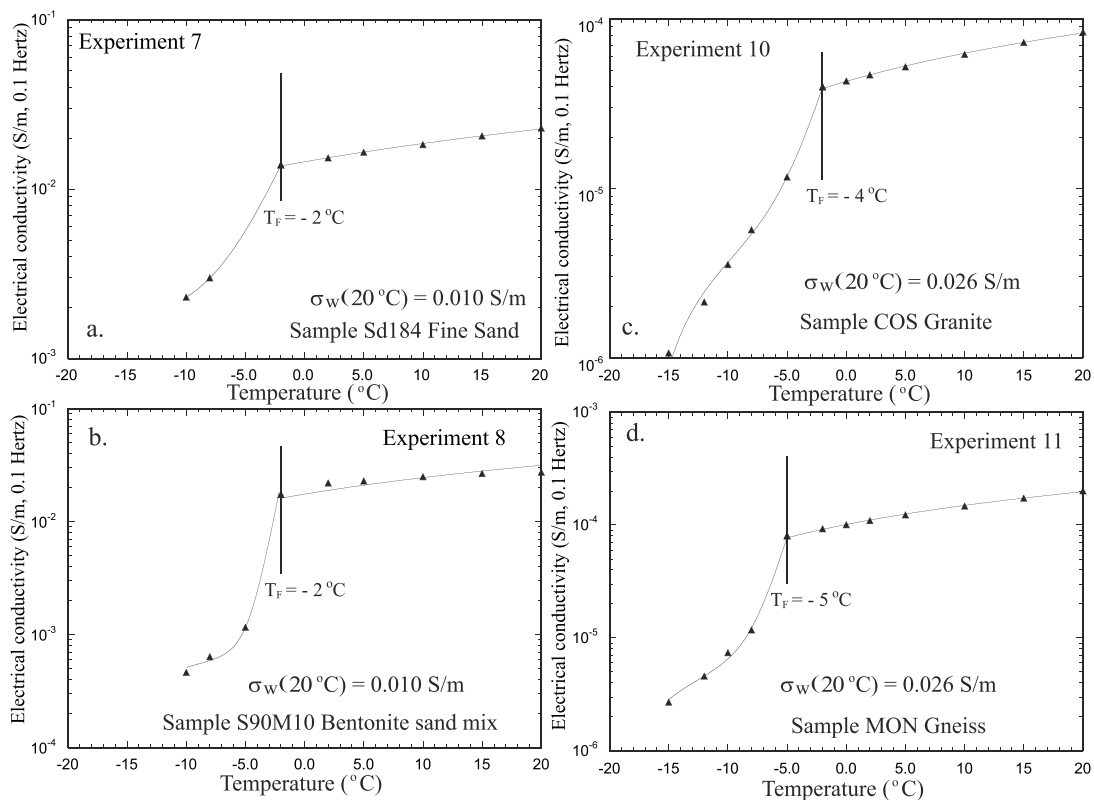

Figure 16. Evolution of the conductivity as a function of the temperature. (a) Electrical conductivity (Experiment 7, soil freezing curve, equation (16)). (b) Electrical conductivity (Experiment 8, soil freezing curve, equation (16)). The variation in electrical conductivity by 1.5 decade between the freezing temperature and $-16{ }^{\circ} \mathrm{C}$ is consistent with Figure 1 in Hoekstra and McNeill (1973). (c) Electrical conductivity (Experiment 10, soil freezing curve, equation (16)). (d) Electrical conductivity (Experiment 11, soil freezing curve, equation 16).

can be estimated at $0.5^{\circ} \mathrm{C}$. In order to avoid noise during the measurements, we stop and disconnect the system of temperature monitoring during the acquisition.

\subsection{Formation Factor and Surface Conductivity Above the Freezing Point}

The electrical conductivity of the rock samples was first measured at different pore water conductivities $\sigma_{w}$ at room temperature $\left(20^{\circ} \mathrm{C}\right)$. The solutions were prepared with pure dehydrated $\mathrm{NaCl}$ crystals and demineralized pore water. The conductivity versus the pore water conductivity plots (e.g., see an example in Figure 7) is used to determine the intrinsic formation factor $F$ and surface conductivity $\sigma_{S}$ by fitting the data to the equation

$$
\sigma=\frac{1}{F} \sigma_{w}+\sigma_{S} .
$$

The values of the formation factor $F$ and surface conductivities $\sigma_{S}$ are reported in Table 1 .

We also determined the connected porosity $\phi$ (dimensionless) and the mass density $\rho\left(\mathrm{kg} / \mathrm{m}^{3}\right)$ using the mass of the saturated material and its volume. The grain density $\rho_{s}$ is assumed to be equal to $2,650 \mathrm{~kg} / \mathrm{m}^{3}$. The measurement of the CEC was determined by the Hexamine cobalt (III) chloride method (Aran et al., 2008; Ciesielski et al., 1997). This technique measures the absorbance of solution (at $472 \mathrm{~nm}$ ) with a calibrated spectrophotometer. The orange color of the Hexamine cobalt (III) chloride solution becomes weaker when cobalt gets sorbed on the surface of mineral (mainly the clay minerals due to their much higher specific surface area). Traditionally, the CEC unit is given in meq/100 $\mathrm{g}$ (see Table 1) and the conversion to the international system of units is $1 \mathrm{meq} / 100 \mathrm{~g}=963.20 \mathrm{C} / \mathrm{kg}$.

In Figure 8a, we plot the (intrinsic) formation factor of the core samples versus their (connected) porosity. We see that the data can be fitted by Archie's law (Archie, 1942) with a cementation exponent $m=2$. In Figure $8 \mathrm{~b}$, we plot the surface conductivity of the material (determined at high frequency of $10 \mathrm{~Hz}$ ) as a function of the CEC normalized by the tortuosity given by the product $F \phi$. The data agree with the prediction of the dynamic Stern layer model (see equation (5)). The slope of the trend can be used to determine the value of the mobility $B$ at room temperature $\left(\sim 20^{\circ} \mathrm{C}\right)$. This value agrees with those derived in our previous studies (e.g., Ghorbani et al., 2018, and references therein). 

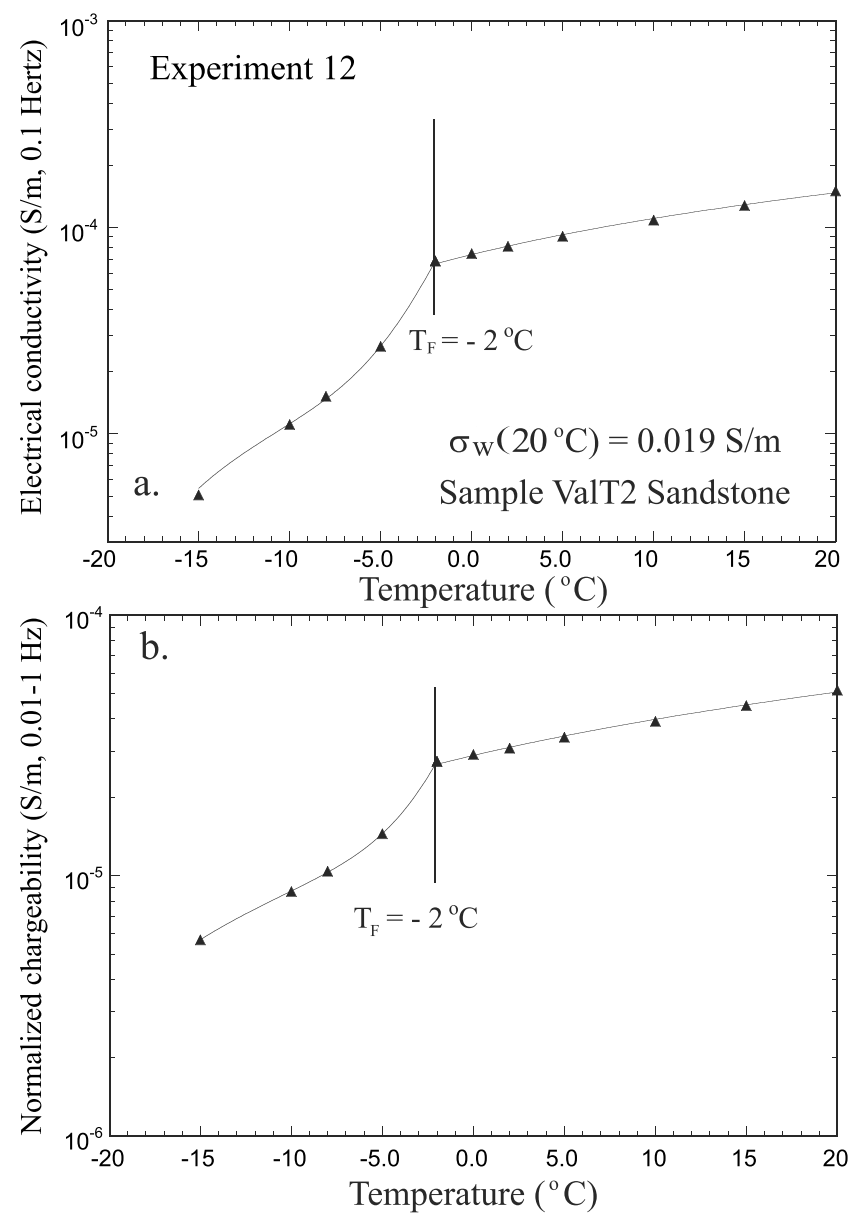

Figure 17. Evolution of the conductivity as a function of the temperature. Experiment12. (a) Electrical conductivity (soil freezing curve, equation (16)). (b) Normalized chargeability (soil freezing curve, equation (16)).

\section{Results}

\subsection{Complex Conductivity Spectra}

Figures 9 and 10 show complex conductivity spectra between $10^{-2} \mathrm{~Hz}$ and $40 \mathrm{kHz}$ at different selected equilibrium temperatures (not all the collected data are shown on these plots). We observe that both the in-phase conductivity and the magnitude of the quadrature conductivity decrease with the decrease of the temperature. In agreement with what is shown in Figure 4, there is a sharp decrease of the magnitude of the two component of the complex conductivity below the freezing temperature, which is not necessarily equal to $0{ }^{\circ} \mathrm{C}$. Figure 9 exhibits another potential polarization mechanism at high frequencies and that could be associated with the polarization of ice (Bjerrum, 1952). In this paper, we will not discuss further this mechanism, which would require the development of a specific polarization model. We will focus instead on the frequency band $10^{-2}-10 \mathrm{~Hz}$, which is also classically the frequency band used in the field in time domain (galvanometric) induced polarization. An example of variation of the in-phase and quadrature conductivities at a given frequency $(1 \mathrm{~Hz})$ is shown in Figure 11 . Hysteresis is likely due the different distribution of the liquid pore water during icing and thaw. The curves look like those predicted in Figure 4. The data show some small hysteretic behavior around the freezing temperature. Since our model does not capture yet such hysteresis, we will focus on the freezing curves below.

\subsection{Normalized Chargeability and Quadrature Conductivity}

Before going to a comparison between our model and the data, we first focus on the relationship between the quadrature conductivity and the normalized chargeability. The normalized chargeability measures the dispersion of the in-phase conductivity curve. In Figure 12, we plot the normalized chargeability (here defined as the difference of the in-phase conductivity between two frequencies $10^{-2}$ and $1.0 \mathrm{~Hz}$ ) and the quadrature conductivity at the geometric mean frequency of $0.1 \mathrm{~Hz}$. We see a high degree of correlation between the two parameters whatever the temperature including for temperatures below the freezing point. Therefore, the normalized chargeability can be taken as a proxy of the quadrature conductivity (or vice versa). By applying equation (8), the model predicts a slope given by $\alpha \approx(2 / \pi) \ln 10^{2}=2.93$, which is very close to the observed value of the slope (2.89).

Table 3

List of the Optimized Parameters for the In-Phase Conductivity

\begin{tabular}{lllllll}
\hline Experiment & \multicolumn{1}{c}{$\sigma^{\prime}\left(T_{0}\right)$} & $\alpha_{T}$ & $\mathrm{E}_{\mathrm{a}}$ & $\sigma_{r}\left(-10^{\circ} \mathrm{C}\right)$ & $\theta_{r}$ & $T_{c}$ \\
\hline$\# 1$ & 0.212 & 0.018 & 17,130 & 0.0061 & 0.03 & $-1.13 \pm 0.09$ \\
$\# 2$ & 0.093 & 0.026 & 28,187 & 0.0014 & 0.02 & $-0.83 \pm 0.03$ \\
$\# 3$ & 0.417 & 0.019 & 17,503 & 0.0089 & 0.03 & $-0.93 \pm 0.03$ \\
$\# 4$ & 0.016 & 0.019 & 10,595 & 0.0001 & 0.01 & $-1.89 \pm 0.08$ \\
$\# 5$ & 0.031 & 0.025 & 27,819 & 0.0002 & 0.008 & $-2.14 \pm 0.16$ \\
$\# 6$ & 0.178 & 0.019 & 17,972 & 0.0010 & 0.009 & $-2.96 \pm 0.13$ \\
$\# 7$ & 0.025 & 0.017 & 14,983 & 0.0006 & 0.025 & $-2.69 \pm 0.08$ \\
$\# 8$ & 0.035 & 0.020 & 6,914 & 0.0006 & 0.023 & $-0.82 \pm 0.04$ \\
$\# 9$ & 0.296 & 0.019 & 19,078 & 0.0007 & 0.006 & $-1.04 \pm 0.24$ \\
$\# 10$ & $9.28 \times 10^{-5}$ & 0.022 & 22,097 & $7.84 \times 10^{-6}$ & 0.006 & $-2.02 \pm 0.11$ \\
$\# 12$ & $2.20 \times 10^{-4}$ & 0.021 & 23,272 & $8.77 \times 10^{-6}$ & 0.006 & $-1.31 \pm 0.20$ \\
\hline
\end{tabular}

Note. The conductivity $\sigma\left(T_{0}\right)$ and the residual conductivity $\sigma_{r}\left(-10^{\circ} \mathrm{C}\right)$ are reported in Siemens per meter. The sensitivity coefficient $\alpha_{T}$ is expressed in per degree Celsius, the activation energy $E_{a}$ in kilojoule per mole, and the residual water content $\theta_{r}$ is dimensionless. Both $\alpha_{T}$ and $E_{a}$ are determined above the freezing condition using the linear and Arrhenius models, respectively. 
Table 4

List the Optimized Parameters for the Normalized Chargeability

\begin{tabular}{lcccc}
\hline Experiment & $M_{n}\left(T_{0}\right)$ & $\alpha_{T}$ & $\mathrm{E}_{\mathrm{a}}$ & $T_{c}$ \\
\hline$\# 1$ & $1.5 \times 10^{-3}$ & 0.024 & 26213 & $-1.25 \pm 0.05$ \\
$\# 2$ & $7.4 \times 10^{-6}$ & 0.025 & 10916 & $-0.50 \pm 0.01$ \\
$\# 3$ & $1.9 \times 10^{-3}$ & 0.019 & 19178 & $-0.74 \pm 0.46$ \\
$\# 4$ & $3.6 \times 10^{-4}$ & 0.024 & 25885 & $-1.82 \pm 0.08$ \\
$\# 5$ & $1.1 \times 10^{-3}$ & 0.028 & 35052 & $-1.47 \pm 0.23$ \\
$\# 6$ & $1.2 \times 10^{-3}$ & 0.018 & 16120 & $-0.69 \pm 0.04$ \\
$\# 7$ & - & - & - & - \\
$\# 8$ & - & - & - & - \\
$\# 9$ & - & - & 18327 & - \\
$\# 10$ & - & - & - & - \\
$\# 11$ & - & - & - & - \\
$\# 12$ & $5.6 \times 10^{-5}$ & 0.019 & 18933 & $-2.19 \pm 0.05$ \\
\hline
\end{tabular}

Note. The normalized chargeability $M_{n}\left(T_{0}\right)$ is reported in Siemens per meter. The sensitivity coefficient $\alpha_{T}$ is expressed in degrees Celsius.

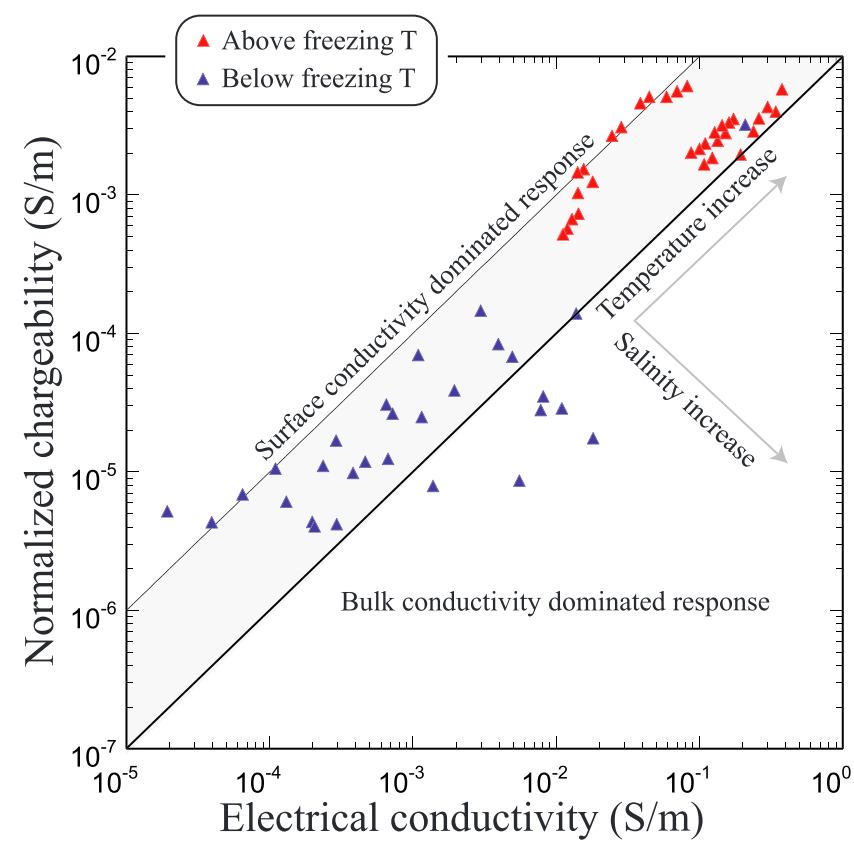

Figure 18. Comparison between the normalized chargeability versus the conductivity for the samples used in this study with the exception of sample ValT2, which is rich in graphite. We consider the full temperature range. The normalized chargeability is here the normalized chargeability determined over two decades times a correction factor of 3 (as explained in the main text) in order to have the total normalized chargeability from DC to high frequency conditions. The upper line corresponds to the limiting case for which surface conductivity dominates the conductivity response and therefore $M_{n} / \sigma_{\infty}=R \approx 0.10$. The lower line would correspond to the limit for which the bulk conductivity starts to dominate the conductivity response (the gray band corresponds to the area where surface conductivity dominates the conductivity response). All the points above the upper line can only be explained by the presence of metallic particles (such as graphite) in the porous material (in the present case the sandstone from Val Thorens). The domain corresponding to the bulk conductivity-dominated response contains data with materials of low cation exchange capacity and/or high salinity. Blue: data below the freezing temperature. Red: Data above the freezing temperature.

\subsection{Conductivity and Normalized Chargeability Versus Temperature Above Freezing Point}

The conductivity (at $0.1 \mathrm{~Hz}$ ) and normalized chargeability (between 0.01 and $1.0 \mathrm{~Hz}$ ) are reported as a function of the temperature in Figures 1317 for the 12 experiments performed in this study. Above the freezing temperature (typically between 0 and $-5{ }^{\circ} \mathrm{C}$ ), the conductivity and normalized chargeability increases slightly with the temperature in agreement with

$$
\begin{gathered}
\sigma^{\prime}(T)=\sigma^{\prime}\left(T_{0}\right)\left[1+\alpha\left(T-T_{0}\right)\right], \\
M_{n}(T)=M_{n}\left(T_{0}\right)\left[1+\alpha\left(T-T_{0}\right)\right] .
\end{gathered}
$$

We obtain $\alpha_{T}=0.019 \pm 0.01$ for the in-phase conductivity data and $\alpha_{T}=0.021 \pm 0.01$ for the normalized chargeability data. These values are in agreement with the values discussed in section 2 above, especially the value predicting correctly the eutectic temperature $\left(\alpha_{T}=0.0217\right)$. Similarly, the same data are equally well fitted with Arrhenius's law. The corresponding activation energies are reported in Tables 3 and 4 . The average value of the activation energy $E_{a}$ is $18,500 \pm 2,000 \mathrm{~kJ} / \mathrm{Mol}$ for the electrical conductivity and 19,100 $\pm 2,600 \mathrm{~kJ} / \mathrm{Mol}$ for the normalized chargeability. The extrapolation of Arrhenius's law at very low temperature would not predict the eutectic temperature unless the activation energy is adjusted. Therefore, we will prefer below the linear temperature correction discussed in section 2 above.

\subsection{Conductivity and Normalized Chargeability Versus Temperature Below Freezing Point}

Figures 13-17 show the fit of the data for the conductivity and the normalized chargeability as a function of the temperature by combining the Gaussian freezing curve for the water content with the linear model for the temperature dependence of the mobilities. We see that the model fit the data well. The fitting parameters are reported in Tables 3 and 4 . We have tried to plot the residual porosity obtained by fitting the conductivity and normalized chargeability curves to the values determined from the CEC (Appendix A and Table 1). Despite the fact that the ranges of values are the same, we could not find a linear correlation between the two quantities.

In Figure 18, we plot the normalized chargeability as a function of the conductivity. From equations (17) and (19), the slope of the trend is independent of temperature (since $\Theta(T)$ cancel each over) and is given by

$$
\frac{M_{n}}{\sigma_{\infty}}=\frac{\rho_{g} \lambda\left(T_{0}\right) \mathrm{CEC}}{\phi \sigma_{w}\left(T_{0}\right)+\rho_{g} B\left(T_{0}\right) \mathrm{CEC}}
$$

Indeed $\lambda(T), B(T)$, and $\sigma_{w}(T)$ have all the same temperature dependences. Two things emerge from equation (24). The first is that at a given salinity, this slope is constant and independent of temperature. This explains the linear trends in the data observed in Figure 18. If salinity increases, the 


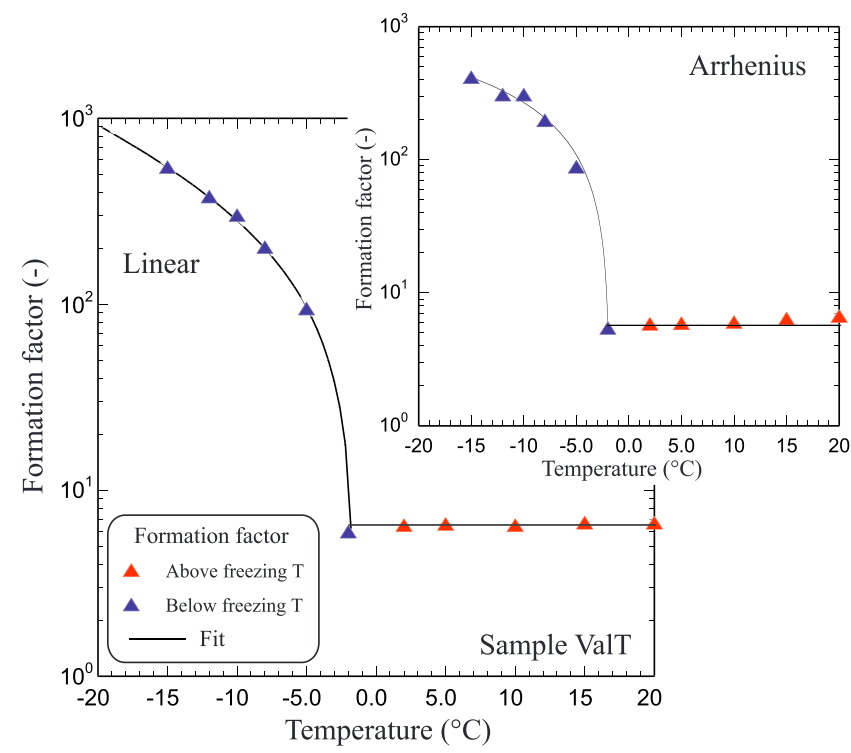

Figure 19. Evolution of the formation factor as a function of the equilibrium temperature (from Experiments 4, 5, and 6, sample ValT). The change below the freezing temperature reflects the change in the water content of the material (fit with an exponential decay function). Insert: Same work using an Arrhenius law with an activation energy of $23 \mathrm{~kJ} / \mathrm{Mol}$ to determine the conductivity of the pore water between $+20^{\circ} \mathrm{C}$ and $-12{ }^{\circ} \mathrm{C}$. Using equation (B6) of Appendix A, we obtain $T_{F}=-2{ }^{\circ} \mathrm{C}, \beta=63^{\circ} \mathrm{C}$, and $F_{r}=$ 2202.

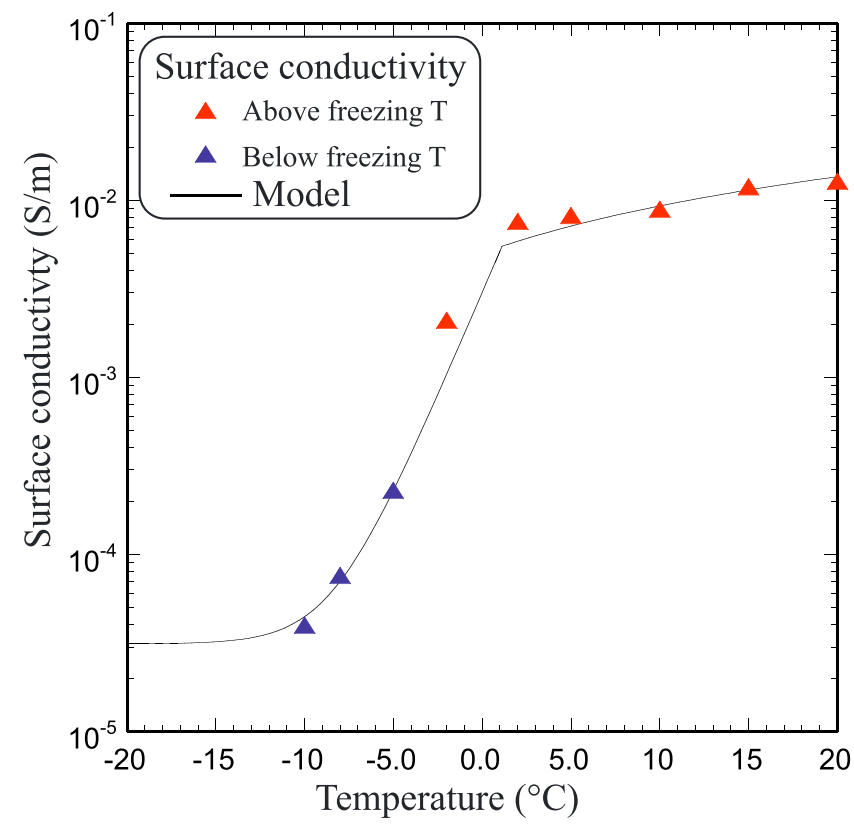

Figure 20. Evolution of the surface conductivity as a function of the equilibrium temperature (determined from Experiments 4, 5, and 6, sample ValT). The result is independent of the choice of the conductivity function (linear or Arrhenius) for the conductivity of the pore water. The change below the freezing temperature reflects the change in the water content of the material. The fit below the freezing temperature is obtained with an exponential growth curve. If the data above the freezing temperature are fitted with a linear model, the sensitivity coefficient is $\alpha_{T}=0.027 \pm 0.003 /{ }^{\circ} \mathrm{C}$ $\left(r^{2}=0.87\right)$. If we use an Arrhenius equation instead, we obtain an activation energy of $E_{a}=29 \pm 8 \mathrm{~kJ} / \mathrm{Mol}\left(r^{2}=0.81\right)$. slope decreases. At low salinities, there is a unique trend corresponding to the surface conductivity case given by

$$
\lim _{\sigma_{w}\left(T_{0}\right) \rightarrow 0}\left(\frac{M_{n}}{\sigma_{\infty}}\right)=\frac{\lambda\left(T_{0}\right)}{B\left(T_{0}\right)}=R=0.09 .
$$

This trend is clearly identified in Figure 18 (upper line labelled "surface conductivity dominated response"). The only data that are above this line correspond to the graphitic sandstone ValT2 (not shown on the plot).

We can go one step further and determine the formation factor and surface conductivity as a function of the temperature taking advantage of Experiments 4, 5, and 6, which are performed with the same core sample (ValT) at three different salinities. The conductivities of the pore water have been measured at $20^{\circ} \mathrm{C}$ and then extrapolated at nine other temperatures using either equation (10) (linear model) or equation (11). Then at each temperature, we plot the conductivity of the rock sample as a function of the conductivity of the pore water. We fit equation (B1) to the data to determine at each temperature $F(\theta)$ and $\sigma_{S}(\theta)$. The results are shown in Figures 19 and 20, respectively. We observe that the surface conductivity does not depend on the model used to compute the conductivity of the pore water. There is however a small difference for the formation factors.

The formation factor is constant above the freezing temperature and sharply decreases below this temperature. For the data obtained with the Arrhenius equation for the pore water conductivities, the formation factors can be fitted by equation (B6) of Appendix B, which can be used to determine the residual formation factor associated with the residual pore water content. In the case where the salt remains in the residual pore water, this residual formation factor is connected to the residual water content by

$$
F_{r}=\frac{1}{\phi \theta_{r}}
$$

For the soil sample, its porosity is $\phi=0.39$, the residual formation factor is $F_{r}=2,202$ and therefore, the residual water content is determined to be $\theta_{r}$ $=1 \times 10^{-3}$.

For the surface conductivity, the data above the freezing temperature can be fitted with a linear model (equation (10)) with $\alpha_{T}=0.027 \pm 0.003\left(r^{2}=\right.$ 0.87) or Arrhenius equation (equation (11)) and we obtain an activation energy of $E_{a}=29 \pm 8 \mathrm{~kJ} / \mathrm{Mol}\left(r^{2}=0.81\right)$. We can also check that the data and the model are consistent by plotting the normalized chargeability data as a function of the surface conductivity values. The results, shown in Figure 21, indicate indeed that the experimental data and the model are completely consistent since the expected slope of the linear trend is equal to $R=0.10$.

In Figure 22, we plot the product of the apparent formation factor by the surface conductivity. According to Appendix B this product is given by

$$
F(\theta) \sigma_{S}(\theta)=\frac{\rho_{g} B C E C}{\phi}
$$

It follows that this product is independent of the water content and depends only on the temperature through the dependence of $B(T)$ with 


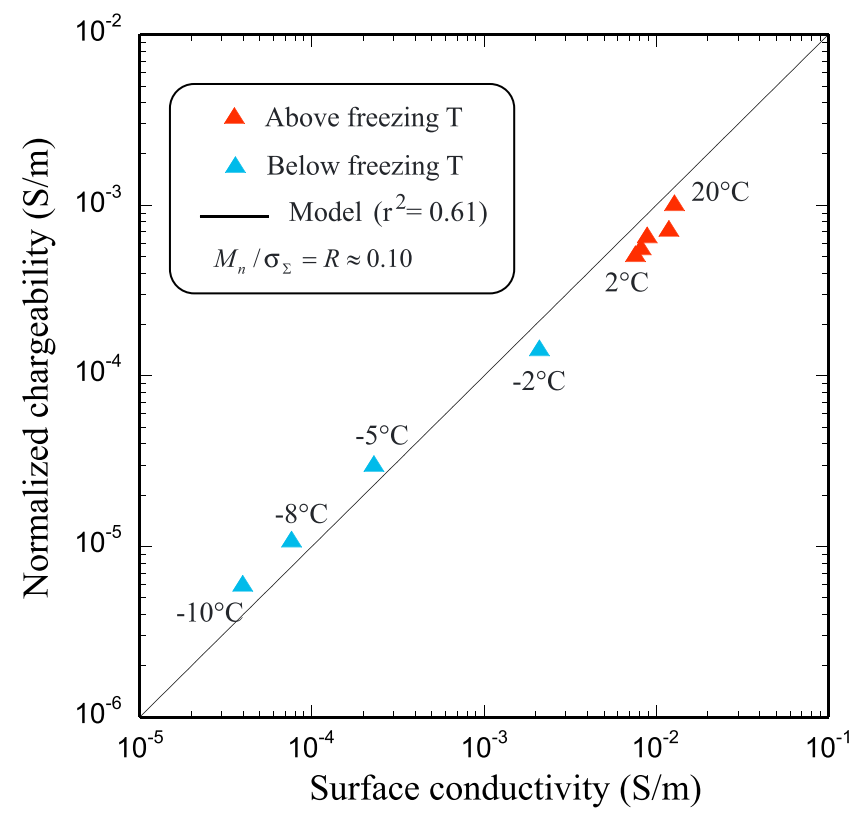

Figure 21. Comparison between the normalized chargeability versus the surface conductivity for sample ValT. We consider the full temperature range. The normalized chargeability is here the normalized chargeability determined over two decades times a correction factor of 3 (as explained in the main text) in order to have the total normalized chargeability from DC to high-frequency conditions. The dynamic Stern layer model predicts that the ration between these two quantities is given by $M_{n} / \sigma_{S}=R \approx 0.10$, which is in perfect agreement with the data.

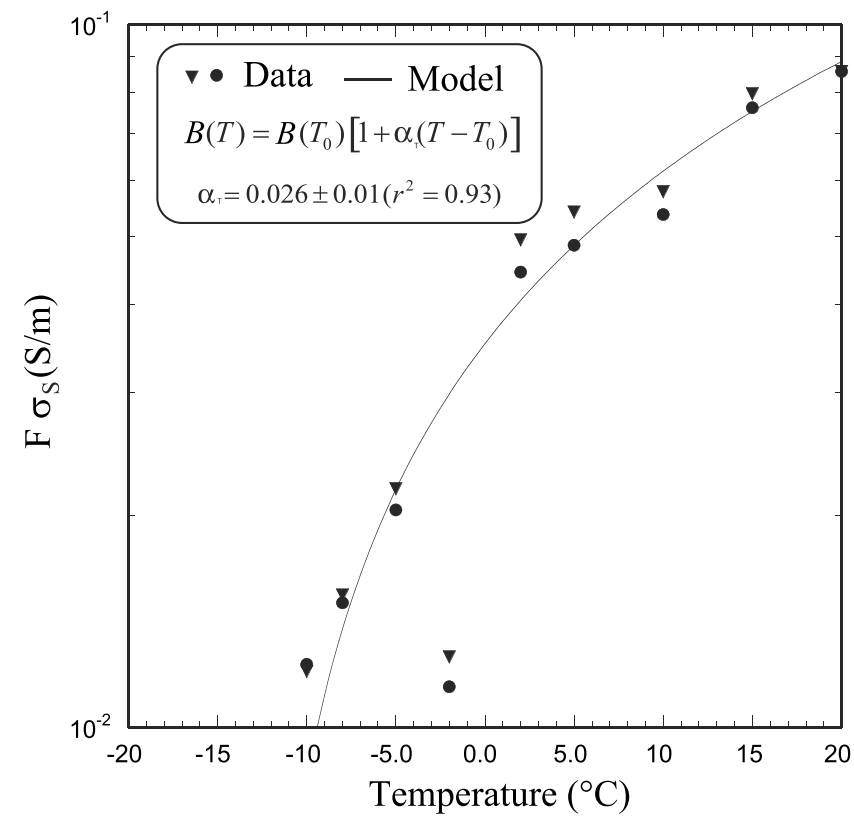

Figure 22. Product of the formation factor by the surface conductivity (determined from Experiments 4, 5 and 6, sample ValT, filled circle: determined from the linear law for the pore water conductivity, filled triangles: determined from the Arrhenius law). This product should depend only on the dependence of the ionic mobility with the temperature. It is fitted here with equation (10) (linear temperature dependence). If we use equation (11) instead (Arrhenius law), the fit is not as good $\left(r^{2}=0.89\right.$ instead of 0.92).
$T$. We see in Figure 22 that the data are well fitted by the linear model (equation (9)) with $\alpha_{T}=0.026 \pm 0.001 /{ }^{\circ} \mathrm{C}$ with a fitting coefficient $r^{2}=$ 0.92 (Arrhenius law leads to $E_{a}=35 \mathrm{~kJ} / \mathrm{Mol}$ with a smaller regression coefficient $r^{2}=0.89$ ). We conclude that the linear equation (10) appears perhaps as a better tool to assess the temperature of the mobilities with temperature than the Arrhenius equation. Finally, in Figure 23, we use equation (26) to compute the water content as a function of the temperature. We check that above the freezing point, the water content equals the porosity. Below the freezing point, the water content can be fitted with equation (16).

\section{Discussion}

The model developed in this paper should only be considered as a preliminary step in modeling induced polarization processes in frozen porous media. First, we have assumed a very simple complex conductivity model in which bulk and surface conductivities act in parallel. We know that when conductivity is restricted to the interface between the mineral surface and the pore space, the tortuosity for conduction current is larger than the tortuosity of the bulk pore space (see recently Revil, Soueid Ahmed, et al., 2018). This change in tortuosity is not accounted for in the electrical conductivity model we used.

It would be interesting as well to consider the microscopic process of ice formation in porous media and the role of the pore size distribution, specific surface area, and salt concentration and to upscale the process to an elementary volume of porous material. This would allow a better understanding of the freezing curve. In turn, experiments that would be done measuring jointly the NMR and complex conductivity could be used to discriminate between different models and to get a better understanding of the freezing process and its impact on the electrical properties of freezing porous materials. Similarly, this could offer a better way to characterize hysteresis during freeze and thaw and to understand how complex conductivity could be better used to monitor hysteresis.

In this paper, we have not tried to model the permeability evolution of the material undergoing freezing. In principle, a unified transport model would propose a relative permeability model combined with the freezing curve for the water content. Since induced polarization is sensitive to permeability (Revil et al., 2015), it would be interesting to see if this method could be used to determine the relative permeability in freezing conditions. In addition, another electrical method called the streaming potential method can be used to assess rock flow properties of frozen media and snow (e.g., Kulessa et al., 2012).

Another topic worth discussing is the use of the present results for field conditions. The model we have developed can be used in concert with numerical modeling of the temperature/water content evolutions during freeze and thaw (e.g., Amiri et al., 2018; McKenzie et al., 2007). These approaches can be used to predict the complex conductivity response in field conditions and to use geophysical time lapse tomography to infer the temperature as a function of space and time. Since in frozen rocks, temperature can be important to understand the hydromechanical properties of the rock/ice mixture (see Krautblatter et al., 2012, 2013; Magnin et al., 2015), time lapse induced polarization tomography could be very important in the near future to monitor frozen rock slope at 


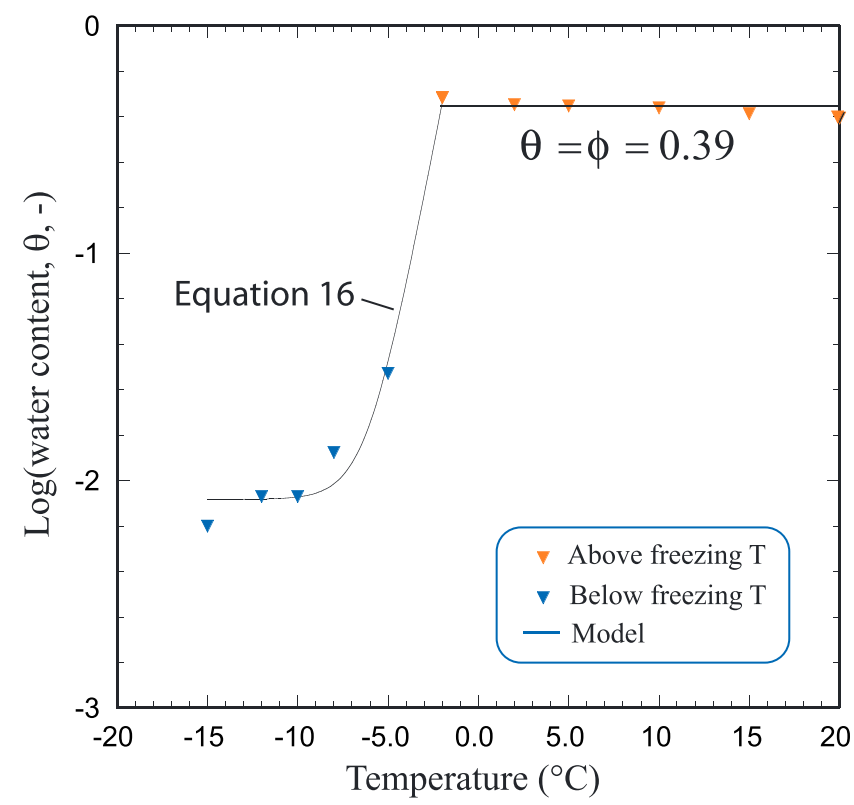

Figure 23. Water content versus temperature determined from the formation factor curve (determined from Experiments 4, 5, and 6, sample ValT). The data show that the water content is constant above the freezing temperature and is fairly well represented by equation (16) below the freezing temperature $\left(\theta_{r}=0.008 \pm 0.001, T_{C}=-1.0 \pm 0.1^{\circ} \mathrm{C}, r^{2}=0.986\right)$. high altitude since their temperature may evolve over time due to climate change.

\section{Conclusion}

We have developed a database looking at the effect of freeze and thaw on the electrical conductivity and normalized chargeability of various types of porous media including soils, sands, sand montmorillonite mixes, a graphitic sandstone, and two crystalline rocks. The spectral induced polarization data were acquired in the frequency range $0.01 \mathrm{~Hz}$ to $40 \mathrm{kHz}$, and porosity and CEC were independently obtained showing a broad range in these properties. The following conclusions have been reached.

1. We focus on the low-frequency band $(0.01-10 \mathrm{~Hz})$ to avoid the effect of ice polarization that occurs at higher frequencies. In this frequency band, above the freezing temperature, the conductivity and normalized chargeability depends linearly on the temperature with an increase of roughly $2 \%$ per degree Celsius. The freezing temperature is typically in the range 0 to $-5{ }^{\circ} \mathrm{C}$ depending on both the salinity and the clay content.

2. According to the constant phase model (also called Drakes's model), the normalized chargeability and the quadrature conductivity (determined at the geometric mean frequency of the frequencies used to determine the normalized chargeability) are proportional to each other. The value of the proportionality constant can be determined from the values of the two frequencies. This relationship is tested for our data set taking data above and below the freezing temperature. We found that this relationship is very precise and the proportionality constant can be accurately predicted from the theory. This means that the normalized chargeability can be used as a proxy of the quadrature conductivity and vice versa even in freezing conditions.

3. We consider that the soil freezing curve takes the form of an exponential growth curve for the water content. Combined with the dynamic Stern layer model predictions for conductivity and normalized chargeability, this soil freezing curve can be used to predict the trend between the conductivity and the normalized chargeability versus temperature below the freezing temperature. The new equations provide a simple and reliable model to predict the effect of temperature upon the conductivity and normalized chargeability in the low-frequency band $(0.01-10 \mathrm{~Hz})$. The parameters describing the soil freezing curve are reported for the different types of materials investigated in our study.

4. Performing measurements on the same rock/soil sample at different salinities allows reconstructing the formation factor and surface conductivity above and below the freezing point. From these data, we can determine the water content versus temperature as well as the temperature dependence of the mobility entering the expression of the surface conductivity.

In the future, it will be important to model the polarization of the ice in order to develop a unified model of polarization in a broad frequency range. Furthermore, it will be important to develop a better understanding of the ice formation at the pore level during freeze and thaw. Finally, we think it would be great to measure simultaneously the NMR and induced polarization spectra during freeze and thaw to test further the present model.

\section{Appendix A: Residual Water Content}

Our goal in this section is to develop a relationship between the residual water content and the CEC of the material. The residual water content depends on the grain scale, the water composition, and the surface properties (for more detail, see, e.g., Leão \& Tuller, 2014; Tokunaga, 2009). We assume that the residual water corresponds to the bound or hydration water covering the surface of the grains which has typically a thickness of two or three layers of water molecules (Israelachvili, 2011; Or \& Tuller, 1999; Tuller \& Or, 2005). In the case of two layers the residual water content is given by 


$$
\theta_{r}=2 d \frac{S}{V_{p}}
$$

where $d(\mathrm{~m})$ corresponds to the diameter of a water molecule $(0.28 \mathrm{~nm}), S\left(\mathrm{~m}^{2}\right)$ is the surface area of the grains, and $V_{p}$ the pore volume $\left(\mathrm{m}^{3}\right)$. The ratio $S / V_{p}$ is related to the excess of charge per unit pore volume by

$$
Q_{V}=Q_{S} \frac{S}{V_{p}}
$$

where $Q_{V}$ denotes the excess of electrical charge per unit of pore volume $\left(\mathrm{C} / \mathrm{m}^{3}\right)$ and $Q_{S}$ denotes the surface charge density (typically $0.90 \mathrm{C} / \mathrm{m}^{2}$; Ghorbani et al., 2018). In addition, the volumetric charge density is related to the $\mathrm{CEC}$ of the material by

$$
Q_{V}=\rho_{g}\left(\frac{1-\phi}{\phi}\right) \mathrm{CEC}
$$

Using equation (A3), we have determined the values of the excess of charge in Table 1 for our core samples using a grain density of $2,650 \mathrm{~kg} / \mathrm{m}^{3}$. Combining these relationships, we have

$$
\theta_{r}=\left\{\begin{array}{l}
\frac{2 d}{Q_{S}} Q_{V} \text { if } \frac{2 d}{Q_{S}} Q_{V}<\phi \\
\phi \text { if } \frac{2 d}{Q_{S}} Q_{V} \geq \phi
\end{array} .\right.
$$

Therefore, under the assumption that the residual water content corresponds to a film of bound water covering the surface of the mineral grains, we have obtained a relationship between the residual water content and both the porosity and the CEC.

\section{Appendix B: Formation Factor and Surface Conductivity}

The instantaneous conductivity can be expressed as

$$
\sigma_{\infty}=\frac{1}{F(\theta)} \sigma_{w}+\sigma_{S}(\theta)
$$

where from the model developed in section 2.1, the apparent formation factor and surface conductivity can be written as

$$
\begin{gathered}
F(\theta)=\phi^{-1} \theta^{-m+1}, \\
\sigma_{S}(\theta)=\theta^{m-1} \rho_{g} B \text { CEC. }
\end{gathered}
$$

Equation (B1) can be used to interpret the measurements performed at different pore water salinities with the same core sample (Experiments 4, 5, 6 in our database). When available, these measurements can be used to determine at each temperature the functions $F(\theta)$ and $\sigma_{S}(\theta)$. To go a bit further and to simplify the presentation, we consider that $m=2$. In this case, we have

$$
\begin{gathered}
\frac{1}{F(\theta, T)}=\phi \theta(T), \\
\sigma_{S}(\theta, T)=\theta(T) \rho_{g} B(T) \mathrm{CEC} .
\end{gathered}
$$

From equation (B4), knowing the porosity, we can estimate the water content $\theta(T)$. An interesting feature of these equation is that the product $F(\theta) \sigma_{S}(\theta)$ is independent of the water content $\theta$ but would have a temperature dependence dictated by $B(T)$. For the formation factor, we found that a good fitting function is given by 


$$
F(T)=\left\{\begin{array}{l}
\left(F-F_{r}\right) \exp \left(-\frac{T-T_{F}}{\beta}\right)+F_{r}, T \leq T_{F} \\
F, T>T_{F}
\end{array}\right.
$$

\section{Acknowledgments}

We thank Ahmad Ghorbani for usefu discussions and Jacques Grangeon for his help with the temperature monitoring system. A. Coperey is funded by a Ph.D. grant from AGIRPOLE-PAGE 2016. This study is part of the transversal project "Ice and Fire". ISTerre is part of Labex OSUG@2020, and OSUG is thanked for funding the project RESOLVE. The numerical data and all the data used to generate the figures can be obtained by sending an email to the corresponding author (A. Revil, andre.revil@univ-smb.fr). They will be provided on ResearchGate upon the publication of the manuscript We thank the Associate Editor and the two anonymous referees for their time and useful comments. where $F_{r}$ is the formation factor associated with the residual water content $\theta_{r}$ and $\beta$ is an empirical fitting constant.

\section{References}

Amiri, E. A., Craiga, J. R., \& Kurylyk, B. L. (2018). A theoretical extension of the soil freezing curve paradigm. Advances in Water Resources, 111, 319-328. https://doi.org/10.1016/j.advwatres.2017.11.021

Anderson, D. M., \& Tice, A. R. (1972). Predicting unfrozen water contents in frozen soils from surface area measurements. Highway Research Record, 393, 12-18.

Aran, D., Maul, A., \& Masfaraud, J.-F. (2008). A spectrophotometric measurement of soil cation exchange capacity based on cobaltihexamine chloride absorbance. Comptes Rendus Geoscience, 340(12), 865-871. https://doi.org/10.1016/j.crte.2008.07.015

Archie, G. E. (1942). The electrical resistivity log as an aid in determining some reservoir characteristics. SPE-942054-G. https://doi.org/ $10.2118 / 942054-G$

Binley, A., Kruschwitz, S., Lesmes, D., \& Kettridge, N. (2010). Exploiting the temperature effects on low frequency electrical spectra of sandstone: A comparison of effective diffusion path lengths. Geophysics, 75(6), A43-A46. https://doi.org/10.1190/1.3483815

Binley, A., Slater, L. D., Fukes, M., \& Cassiani, G. (2005). Relationship between spectral induced polarization and hydraulic properties of saturated and unsaturated sandstone. Water Resources Research, 41, W12417. https://doi.org/10.1029/2005WR004202

Bjerrum, N. (1952). Structure and properties of ice. Science, 115(2989), 385-390. https://doi.org/10.1126/science.115.2989.385

Bleil, D. F. (1953). Induced polarization: A method of geophysical prospecting. Geophysics, 18(3), 636-661. https://doi.org/10.1190/ 1.1437917

Börner, F. D. (1992). Complex conductivity measurements of reservoir properties. In P. F. Worthington, \& C. Chardaire-Riviere (Eds.), Proceedings of the Third European Core Analysis Symposium, Paris, (Vol. 3, pp. 359-386). Neward, N. J.: Harwood Academic.

Brooks, R.H., \& Corey A.T. (1964). Hydraulic properties of porous media, Hydrology Papers, No. 3, Colorado State University, Ft. Collins, Colorado.

Brown, R. J. E. (1970). Permafrost in Canada-Its influence on northern development, (Vol. 234). Toronto: University of Toronto Press

Buchanan, S., Ingham, M., \& Gouws, G. (2011). The low frequency electrical properties of sea ice. Journal of Applied Physics, 110(7), 074908. https://doi.org/10.1063/1.3647778

Chapman, D. L. (1913). A contribution to the theory of electrocapillarity. Philosophical Magazine, 25(148), 475-481. https://doi.org/ $10.1080 / 14786440408634187$

Ciesielski, H., Sterckeman, T., Santerne, M., \& Willery, J. P. (1997). Determination of cation exchange capacity and exchangeable cations in soils by means of cobalt hexamine trichloride. Effects of experimental conditions. Agronomie-Sciences Des Productions Végétales et de l'Environnement, 17(1), 1-8.

Clavier, C., Coates, G., \& Dumanoir, J. (1984). Theoretical and experimental bases for the dual-water model for interpretation of shaly sands. Society of Petroleum Engineers Journal, 24(02), 153-168. https://doi.org/10.2118/6859-PA

Dash, J. G., Fu, H.-Y., \& Wettlaufer, J. S. (1995). The premelting of ice and its environmental consequences. Reports on Progress in Physics, 58(1), 115-167. https://doi.org/10.1088/0034-4885/58/1/003

Doetsch, J., Ingeman-Nielsen, T., Christiansen, A. V., Fiandaca, G., Auken, E., \& Elberling, B. (2015). Direct current (DC) resistivity and induced polarization (IP) monitoring of active layer dynamics at high temporal resolution. Cold Regions Science and Technology, 119, 16-28. https://doi.org/10.1016/j.coldregions.2015.07.002

Duvillard, P. A., Revil, A., Soueid Ahmed, A., Qi, Y., Coperey, A., \& Ravanel, L. (2018). Three dimensional electrical conductivity and induced polarization tomography of a rock glacier. Journal of Geophysical Research: Solid Earth, 123, 9528-9554. https://doi.org/ 10.1029/2018JB015965

Ghorbani, A., Revil, A., Coperey, A., Soueid Ahmed, A., Roque, S., Heap, M. J., et al. (2018). Complex conductivity of volcanic rocks and the geophysical mapping of alteration in volcanoes. Journal of Volcanology and Geothermal Research, 357, 106-127. https://doi.org/10.1016/ j.jvolgeores.2018.04.014

Grimm, R. E., \& Stillman, D. E. (2015). Field test of detection and characterisation of subsurface ice using broadband spectral-induced polarisation: Subsurface ice characterisation using spectral-induced polarisation. Permafrost and Periglacial Processes, 26(1), 28-38. https://doi.org/10.1002/ppp.1833

Hauck, C., Böttcher, M., \& Maurer, H. (2011). A new model for estimating subsurface ice content based on combined electrical and seismic data sets. The Cryosphere, 5(2), 453-468. https://doi.org/10.5194/tc-5-453-2011

Hauck, C., Vonder Mühll, D., \& Maurer, H. (2003). Using DC resistivity tomography to detect and characterize mountain permafrost. Geophysical Prospecting, 51(4), 273-284. https://doi.org/10.1046/j.1365-2478.2003.00375.x

Hermans, T., Nguyen, F., Robert, T., \& Revil, A. (2014). Geophysical methods for monitoring temperature changes in shallow low enthalpy geothermal systems. Energies, 7(8), 5083-5118. https://doi.org/10.3390/en7085083

Hersir, G. P., \& Bjornsson, A. (1991). Geophysical Exploration for Geothermal Resources: Principles and Application. Iceland: United Nations University.

Hilbich, C., Marescot, L., Hauck, C., Loke, M. H., \& Mäusbacher, R. (2009). Applicability of electrical resistivity tomography monitoring to coarse blocky and ice-rich permafrost landforms. Permafrost and Periglacial Processes, 20(3), 269-284. https://doi.org/10.1002/ppp.652 Hobbs, P. V. (2010). Ice physics, Oxford classic texts in the physical sciences. Oxford: Oxford University Press.

Hoekstra, P. (1965). Conductance of frozen bentonite suspensions. Soil Science Society of America Proceedings, 29(5), 519-522. https://doi. org/10.2136/sssaj1965.03615995002900050015x

Hoekstra, P., \& McNeill, D. (1973). Electromagnetic probing of permafrost. In Permafrost, North American Contribution, Second Int. Conf., Yakutsk (p. 517-526). Washington DC: USSR, National Academy of Science.

Ingham, M., Gouws, G., Buchanan, S., Brown, R., \& Haskell, T. (2012). In-situ measurements of the low frequency dielectric permittivity of first-year Antarctic sea ice. Cold Regions Science and Technology, 83-84, 139-146. https://doi.org/10.1016/j.coldregions.2012.07.008

Israelachvili, J. N. (2011). Intermolecular and surface forces. London: Academic press. 
Kellerer-Pirklbauer, A., \& Kaufmann, V. (2017). Deglaciation and its impact on permafrost and rock glacier evolution: New insight from two adjacent cirques in Austria. Science of the Total Environment, 621, 1397-1414. https://doi.org/10.1016/j. scitotenv.2017.10.087

Kneisel, C., Hauck, C., Fortier, R., \& Moorman, B. (2008). Advances in geophysical methods for permafrost investigations. Permafrost and Periglacial Processes, 19(2), 157-178. https://doi.org/10.1002/ppp.616

Krautblatter, M., Funk, D., \& Günzel, F. K. (2013). Why permafrost rocks become unstable: A rock-ice-mechanical model in time and space. Earth Surface Processes and Landforms, 38(8), 876-887. https://doi.org/10.1002/esp.3374

Krautblatter, M., Huggel, C., Deline, P., \& Hasler, A. (2012). Research perspectives on unstable high-alpine bedrock permafrost: Measurement, modelling and process understanding. Permafrost and Periglacial, 23(1), 80-88. https://doi.org/10.1002/ppp.740

Krautblatter, M., Verleysdonk, S., Flores-Orozco, A., \& Kemna, A. (2010). Temperature-calibrated imaging of seasonal changes in permafrost rock walls by quantitative electrical resistivity tomography (Zugspitze, German/Austrian Alps): Quantitative ERT of permafrost rocks. Journal of Geophysical Research, 115, F02003. https://doi.org/10.1029/2008JF001209

Kulessa, B., Chandler, D. M., Revil, A., \& Essery, R. (2012). Theory and numerical modelling of electrical self-potential (SP) signatures of unsaturated flow in melting snow. Water Resources Research, 48, W09511. https://doi.org/10.1029/2012WR012048

Leão, T. P., \& Tuller, M. (2014). Relating soil specific surface area, water film thickness, and water vapor adsorption. Water Resources Research, 50, 7873-7885. https://doi.org/10.1002/2013WR014941

Magnin, F., Krautblatter, M., Deline, P., Ravanel, L., Malet, E., \& Bevington, A. (2015). Determination of warm, sensitive permafrost areas in near-vertical rockwalls and evaluation of distributed models by electrical resistivity tomography. Journal of Geophysical Research: Earth Surface, 120, 745-762. https://doi.org/10.1002/2014JF003351

Marshall, D. J., \& Madden, T. R. (1959). Induced polarization, a study of its causes. Geophysics, 24(4), 790-816. https://doi.org/10.1190/ 1.1438659

McKenzie, J. M., Voss, C. I., \& Siegel, D. I. (2007). Groundwater flow with energy transport and water-ice phase change: Numerical simulations, benchmarks, and application to freezing in peat bogs. Advances in Water Resources, 30(4), 966-983. https://doi.org/10.1016/ j.advwatres.2006.08.008

Melnikov, V. P., Sneqirev, A. M., \& Lyakhov, L. L. (1971). Polyarizuemosti verkhikh gorizontov tolshchi mnogoletnernerzlykh gornykh porod (Polarizability of the upper horizons of permafrost layers). (Geol. Goof) Geology and Geophysics, 7.

Mewes, B., Hilbich, C., Delaloye, R., \& Hauck, C. (2017). Resolution capacity of geophysical monitoring regarding permafrost degradation induced by hydrological processes. The Cryosphere, 11(6), 2957-2974. https://doi.org/10.5194/tc-11-2957-2017

Mollaret, C., Hilbich, C., Pellet, C., Flores-Orozco, A., Delaloye, R., \& Hauck, C. (2018). Mountain permafrost degradation documented through a network of permanent electrical resistivity tomography sites. The Cryosphere Discussions, 1-34. https://doi.org/10.5194/tc2018-272

Murrmann, R. P. (1973). Ionic mobility in permafrost. In Permafrost, North American Contribution, Second Int. Conf., 13-28 July 1973, Yakutsk (p. 352-359). Washington DC: USSR, National Academy of Science.

Niu, Q., Revil, A., \& Saidian, M. (2016). Salinity dependence of the complex surface conductivity of the Portland sandstone. Geophysics, 81(2), D125-D140. https://doi.org/10.1190/geo2015-0426.1

Ogilvy, A. A. (1967). Geophysical studies in permafrost regions in USSR. Mining Groundwater Geophysics (Geol. Survey Canada, Econ. Geol), 26, 641-650.

Olhoeft, G. R. (1977). Electrical properties of natural clay permafrost. Canadian Journal of Earth Sciences, 14(1), 16-24. https://doi.org/ 10.1139/e77-002

Or, D., \& Tuller, M. (1999). Liquid retention and interfacial area in variably saturated porous media: Upscaling from single-pore to samplescale model. Water Resources Research, 35(12), 3591-3605. https://doi.org/10.1029/1999WR900262

O'Sadnick, M., Ingham, M., Eicken, H., \& Pettit, E. (2016). In situ field measurements of the temporal evolution of low-frequency sea-ice dielectric properties in relation to temperature, salinity, and microstructure. The Cryosphere, 10(6), 2923-2940. https://doi.org/10.5194/ tc-10-2923-2016

Parkhomenko, E. I. (1967). Electrical properties of rock. [English Translation]. New York: Pergamon Press.

Potter, R. W., Clynne, M. A., \& Brown, D. L. (1978). Freezing-point depression of aqueous sodium-chloride solutions. Economic Geology, 73(2), 284-285. https://doi.org/10.2113/gsecongeo.73.2.284

Revil, A. (2013a). Effective conductivity and permittivity of unsaturated porous materials in the frequency range $1 \mathrm{mHz}-1 \mathrm{GHz}$. Water Resources Research, 49, 306-327. https://doi.org/10.1029/2012WR012700

Revil, A. (2013b). On charge accumulation in heterogeneous porous rocks under the influence of an external electric field. Geophysics, 78(4), D271-D291. https://doi.org/10.1190/geo2012-0503.1

Revil, A., Binley, A., Mejus, L., \& Kessouri, P. (2015). Predicting permeability from the characteristic relaxation time and intrinsic formation factor of complex conductivity spectra. Water Resources Research, 51, 6672-6700. https://doi.org/10.1002/2015WR017074

Revil, A., Coperey, A., Deng, Y., Cerepi, A., \& Seleznev, N. (2018). Complex conductivity of tight sandstones. Geophysics, 83(2), E55-E74. https://doi.org/10.1190/geo2017-0096.1

Revil, A., Coperey, A., Mao, D., Abdulsamad, F., Ghorbani, A., Rossi, M., \& Gasquet, D. (2018). Induced polarization response of porous media with metallic particles-Part 8. Influence of temperature and salinity. Geophysics, 83(6), E435-E456. https://doi.org/10.1190/ geo2018-0089.1

Revil, A., Coperey, A., Shao, Z., Florsch, N., Fabricius, I. L., Deng, Y., et al. (2017). Complex conductivity of soils. Water Resources Research, 53, 7121-7147. https://doi.org/10.1002/2017WR020655

Revil, A., Ghorbani, A., Gailler, L. S., Gresse, M., Panwar, N., \& Sharma, R. (2018). Electrical conductivity and induced polarization investigations at Kilauea volcano, Hawai'i. Journal of Volcanology and Geothermal Research, 368, 31-50. https://doi.org/10.1016/j. jvolgeores.2018.10.014

Revil, A., Kessouri, P., \& Torres-Verdín, C. (2014). Electrical conductivity, induced polarization, and permeability of the Fontainebleau sandstone. Geophysics, 79(5), D301-D318. https://doi.org/10.1190/geo2014-0036.1

Revil, A., Le Breton, M., Niu, Q., Wallin, E., Haskins, E., \& Thomas, D. M. (2017). Induced polarization of volcanic rocks-1. Surface versus quadrature conductivity. Geophysical Journal International, 208(2), 826-844. https://doi.org/10.1093/gii/ggw444

Revil, A., \& Skold, M. (2011). Salinity dependence of spectral induced polarization in sands and sandstones: Salinity dependence of induced polarization. Geophysical Journal International, 187(2), 813-824. https://doi.org/10.1111/j.1365-246X.2011.05181.x

Revil, A., Soueid Ahmed, A., \& Matthai, S. (2018). Transport of water and ions in partially water-saturated porous media. Part 3. Electrical conductivity. Advances in Water Resources, 121, 97-111. https://doi.org/10.1016/j.advwatres.2018.08.007

Schlumberger, C. (1920). Study of underground electrical prospecting. Paris: Inc. Gauthier-Villars et Cie. 
Sen, P. N., \& Goode, P. A. (1992). Influence of temperature on electrical conductivity on shaly sands. Geophysics, 57(1), 89-96. https://doi. $\operatorname{org} / 10.1190 / 1.1443191$

Sidorova, M. P., \& Fridrikhsberg, D. A. (1973). Study of the induced polarization of systems simulating soils during freezing. In Permafrost, USSR Contribution, Second Int. Conf., 13-28 July 1973, Yakutsk (p. 347-349). Washington D.C: USSR, National Academy of Science.

Siemens, W. (1860). Vorschlag eines reproducirbaren Widerstandsmaaßes. Annalen der Physik und Chemie (in German, 186(5), 1-20. https://doi.org/10.1002/andp.18601860502

Snegirev, A. M., Lyakhov, L. L., \& Melnikov, V. P. (1973). Application of the method of induced polarization for studying fine-grained frozen soils. In Permafrost, USSR Contribution, Second Int. Conf., 13-28 July 1973, Yakutsk (p. 352-354). Washington DC: USSR, National Academy of Science.

Springman, S. M., Yamamoto, Y., Buchli, T., Hertrich, M., Maurer, H., Merz, K., et al. (2013). Rock glacier degradation and instabilities in the European Alps: A characterisation and monitoring experiment in the Turtmanntal, CH. In C. Margottini, P. Canuti, \& K. Sassa (Eds.), Landslide Science and Practice (pp. 5-13). Berlin Heidelberg, Berlin, Heidelberg: Springer. https://doi.org/10.1007/978-3-64231337-0_1

Stern, O. (1924). Zur theorie der electrolytischen Doppelschicht (The theory of the electrolytic double layer). Zeitschrift für Elektrochemie, $30,508-516$.

Tokunaga, T. K. (2009). Hydraulic properties of adsorbed water films in unsaturated porous media: Hydraulic properties of adsorbed water films. Water Resources Research, 45, W06415. https://doi.org/10.1029/2009WR007734

Tuller, M., \& Or, D. (2005). Water films and scaling of soil characteristic curves at low water contents: Scaling of characteristic curves. Water Resources Research, 41, W09403. https://doi.org/10.1029/2005WR004142

Van Genuchten, M. T. (1980). A closed-form equaton for predicting the hydraulic conductivity of unsaturated soils. Soil Science Society of America Journal, 44(5), 892-898. https://doi.org/10.2136/sssaj1980.03615995004400050002x

Van Voorhis, G. D., Nelson, P. H., \& Drake, T. L. (1973). Complex resistivity spectra of porphyry copper mineralization. Geophysics, 38(1), 49-60. https://doi.org/10.1190/1.1440333

Vershinin, P. V., Dcriagin, V. V., \& Kirilenko, N. V. (1949). The nonfreezing water in soil, Acad. Sci. USSR Geogr. Geophys. Ser. 13, (Vol. 108) U.S. Army Arctic Construction and Frost Laboratory (USA ACFEI). Translation No. 301.

Vinegar, H. J., \& Waxman, M. H. (1984). Induced polarization of shaly sands. Geophysics, 49(8), 1267-1287. https://doi.org/10.1190/ 1.1441755

Watanabe, K., \& Mizoguchi, M. (2002). Amount of unfrozen water in frozen porous media saturated with solution. Cold Regions Science and Technology, 34(2), 103-110. https://doi.org/10.1016/S0165-232X(01)00063-5

Waxman, M. H., \& Smits, L. J. M. (1968). Electrical conductivities in oil-bearing shaly sands. Society of Petroleum Engineers Journal, 8(02), 107-122. https://doi.org/10.2118/1863-A

Waxman, M. H., \& Thomas, E. C. (1974). Electrical conductivities in shaly sands-I. The relation between hydrocarbon saturation and resistivity index. II. The temperature coefficient of electrical conductivity. Journal of Petroleum Technology, 26(02), 213-225. https://doi. org/10.2118/4094-PA

Weller, A., Slater, L., \& Nordsiek, S. (2013). On the relationship between induced polarization and surface conductivity: Implications for petrophysical interpretation of electrical measurements. Geophysics, 78(5), D315-D325. https://doi.org/10.1190/geo2013-0076.1

Woodruff, W. F., Revil, A., \& Torres-Verdín, C. (2014). Laboratory determination of the complex conductivity tensor of unconventional anisotropic shales. Geophysics, 79(5), E183-E200. https://doi.org/10.1190/geo2013-0367.1

Zimmermann, E., Kemna, A., Berwix, J., Glaas, W., Münch, H. M., \& Huisman, J. A. (2008). A high-accuracy impedance spectrometer for measuring sediments with low polarizability. Measurement Science and Technology, 19(10), 105603. https://doi.org/10.1088/0957-0233/ $19 / 10 / 105603$ 